\title{
OH column abundance over Table Mountain Facility, California: Intra-annual variations and comparisons to model predictions for 1997-2001
}

\author{
Franklin P. Mills, ${ }^{1,2}$ Richard P. Cageao, ${ }^{1}$ Stanley P. Sander, ${ }^{1,3,4}$ Mark Allen, ${ }^{1,4}$ \\ Yuk L. Yung, ${ }^{4}$ Ellis E. Remsberg, ${ }^{5}$ James M. Russell III, ${ }^{6}$ and Ulf Richter ${ }^{3}$ \\ Received 4 February 2003; revised 14 July 2003; accepted 11 August 2003; published 24 December 2003.
}

[1] Measurements of the $\mathrm{OH}$ column abundance over the Jet Propulsion Laboratory's Table Mountain Facility (TMF) have been made since July 1997 at $10^{\circ}-80^{\circ}$ solar zenith angle using a Fourier transform ultraviolet spectrometer. The measured $\mathrm{OH}$ column at any solar zenith angle is typically larger in the afternoon than in the morning. The variations observed in the $\mathrm{OH}$ column abundance appear to result from changes in atmospheric conditions on a daily or longer timescale. The larger observed variations are statistically significant. Sensitivity coefficients describing how the $\mathrm{OH}$ column abundance is expected to change in response to changes in the concentrations of $\mathrm{H}_{2} \mathrm{O}, \mathrm{O}_{3}, \mathrm{NO}, \mathrm{CO}$, and $\mathrm{CH}_{4}$ have been calculated on the basis of an analytic model. On the basis of these sensitivity coefficients and Halogen Occultation Experiment observations of $\mathrm{O}_{3}$, the net sensitivity of the $\mathrm{OH}$ column abundance to variations in $\mathrm{O}_{3}$ should be close to zero. The observed $\mathrm{OH}$ column abundance over TMF increased by about 25\% from July 1997 to December 2001. This interannual trend in $\mathrm{OH}$ column abundance is not consistent with calculations that incorporate observed trends in $\mathrm{H}_{2} \mathrm{O}$ and $\mathrm{O}_{3}$ and is at least a factor of 2 larger than the calculated difference between solar minimum and maximum. Comparisons between measured and calculated normalized $\mathrm{OH}$ column abundances suggest that the sensitivity of $\mathrm{OH}$ to variations in $\mathrm{H}_{2} \mathrm{O}$ may be a factor of 2 larger than predicted in present models and that there is some other major driver for the observed variability in the $\mathrm{OH}$ column abundance that was not included in the present analysis. INDEX TERMS: 0317 Atmospheric Composition and Structure: Chemical kinetic and photochemical properties; 0340 Atmospheric Composition and Structure: Middle atmosphere-composition and chemistry; 0394 Atmospheric Composition and Structure: Instruments and techniques; 7536 Solar Physics, Astrophysics, and Astronomy: Solar activity cycle (2162); KEYWORDS: hydroxyl, mesosphere, photochemistry

Citation: Mills, F. P., R. P. Cageao, S. P. Sander, M. Allen, Y. L. Yung, E. E. Remsberg, J. M. Russell III, and U. Richter, OH column abundance over Table Mountain Facility, California: Intra-annual variations and comparisons to model predictions for $1997-$ 2001, J. Geophys. Res., 108(D24), 4785, doi:10.1029/2003JD003481, 2003.

\section{Introduction}

[2] Although it contains only about $15 \%$ of the total ozone column, the distribution of ozone in the $30-70 \mathrm{~km}$ altitude region of the atmosphere affects global stratospheric temperatures and circulation [Müller et al., 1999]. This

\footnotetext{
${ }^{1}$ Jet Propulsion Laboratory, California Institute of Technology, Pasadena, California, USA.

${ }^{2}$ Now at Research School of Physical Sciences and Engineering, Australian National University, Canberra, ACT, Australia.

${ }^{3}$ Division of Engineering and Applied Science, California Institute of Technology, Pasadena, California, USA.

${ }^{4}$ Division of Geological and Planetary Sciences, California Institute of Technology, Pasadena, California, USA.

${ }^{5}$ NASA Langley Research Center, Hampton, Virginia, USA.

${ }^{6}$ Center for Atmospheric Sciences, Hampton University, Hampton, Virginia, USA.

Copyright 2003 by the American Geophysical Union. 0148-0227/03/2003JD003481
}

region also is believed to be the region in which the first evidence for a recovery of ozone toward pre-industrial levels may be observed [Hofmann et al., 1999]. To properly identify the recovery of ozone from anthropogenic influences, the natural chemistry must be understood. Ozone loss in the upper stratosphere and lower mesosphere is believed to be dominated by reactions involving chlorine oxides $\left(\mathrm{ClO}_{x}\right)$ and odd-hydrogen species $\left(\mathrm{HO}_{x}=\mathrm{H}+\mathrm{OH}+\right.$ $\mathrm{HO}_{2}+\mathrm{H}_{2} \mathrm{O}_{2}$ ), so a good understanding of both $\mathrm{HO}_{x}$ and $\mathrm{ClO}_{x}$ chemistry is needed. Measurements of $\mathrm{OH}$ are a direct probe of the chemistry in this region because $\mathrm{OH}$ is a key species in many of the most important reactions. The most recent observations of $\mathrm{OH}, \mathrm{HO}_{2}$, and $\mathrm{O}_{3}$ have not agreed satisfactorily with photochemical model calculations based on existing laboratory data [Jucks et al., 1998; Sandor and Clancy, 1998; Conway et al., 2000], and significant revisions to the standard chemistry for the mesosphere and upper stratosphere have been proposed. Those studies, however, examined measurements collected over limited 
periods of time, so they have sampled only a small fraction of the range of conditions that may exist in the stratosphere and mesosphere.

[3] One additional tool that may be used for analyzing the daytime photochemistry in the upper stratosphere and mesosphere is column-integrated measurements of $\mathrm{OH}$ abundance collected throughout the day for at least several days per month over an extended period of time. A large majority of the $\mathrm{OH}$ column is at $30-70 \mathrm{~km}$ altitude, so the $\mathrm{OH}$ column abundance should be sensitive to the photochemical state of this region. This paper describes the first 3.5 years of measurements of the $\mathrm{OH}$ column abundance over the Jet Propulsion Laboratory's (JPL) Table Mountain Facility (TMF) at 34.4N, - 117.7E. An analytical photochemical model [Pickett and Peterson, 1996] was updated and used to determine the primary geophysical parameters that should control variations in $\mathrm{OH}$ column abundance. These were found to be $\mathrm{O}_{3}$ and $\mathrm{H}_{2} \mathrm{O}$. We then compare the observed intra-annual variations in $\mathrm{OH}$ column to calculations based on observed variations in the precursor species, $\mathrm{O}_{3}$ and $\mathrm{H}_{2} \mathrm{O}$, with the aid of the updated analytical photochemical model.

[4] Profiles for $\mathrm{OH}$ in the stratosphere and mesosphere have been measured by several groups since the early 1980s [Canty et al., 2000]. Three recent studies [Jucks et al., 1998; Conway et al., 2000; Summers et al., 1997] have been particularly important because $\mathrm{OH}$ profiles were measured simultaneously with those of other relevant species $\left(\mathrm{O}_{3}\right.$, $\mathrm{H}_{2} \mathrm{O}$, and/or $\mathrm{HO}_{2}$ ). These three studies concluded that present photochemical models do not accurately capture the actual $\mathrm{HO}_{x}$ chemistry in the stratosphere and mesosphere. The most recent study [Conway et al., 2000] concluded that none of the previously proposed revisions to the accepted chemical kinetic rates could satisfactorily explain the differences between calculated and measured $\mathrm{OH}$ abundances throughout the upper stratosphere and mesosphere.

[5] OH column measurements have been made over Fritz Peak Observatory, Colorado, (FPO) since 1977 [Burnett and Burnett, 1996], over Tokyo, Japan, in 1992-1995 [Iwagami et al., 1998], and over Socorro, New Mexico (NMT), since 1996 [Burnett and Minschwaner, 1998; Canty et al., 2000]. Long-term measurement records, such as these, are necessary for determining statistically significant correlations between $\mathrm{OH}$ column abundance and climatic or dynamic changes in the upper stratosphere and mesosphere. Temporal variations in the $\mathrm{OH}$ column abundance on seasonal to decadal timescales have been reported for all three sites [Burnett and Burnett, 1996; Iwagami et al., 1998]. These temporal variations have not been satisfactorily explained in terms of relevant geophysical parameters, partly because of the difficulties involved in interpreting column measurements.

[6] The column abundance of $\mathrm{OH}$ over Table Mountain Facility (TMF), California, has been measured regularly since July 1997 using the Fourier transform ultraviolet spectrometer [Cageao et al., 2001]. One motivation for initiating these measurements is the large (and unexplained) differences among the previous $\mathrm{OH}$ column measurements and the significant differences between all of the $\mathrm{OH}$ column measurements and model calculations [Iwagami et al., 1998]. For example, the annual average $\mathrm{OH}$ column observed for $1998-2000$ over TMF is $10-20 \%$ larger than that observed by another group over Tokyo for 1992-1995; $30-65 \%$ smaller than that observed by other groups over Colorado and New Mexico for 1980-1996; and 15-30\% smaller than calculated by photochemical models [Mills et al., 2002]. However, three different types of instruments and two different measurement approaches were used at these four sites. All $\mathrm{OH}$ column measurements require a method for inferring (or removing) the exoatmospheric solar spectrum which has deep Fraunhofer lines that interfere with the terrestrial $\mathrm{OH}$ features. As discussed by Cageao et al. [2001] and Mills et al. [2002], the measurement and analysis methods used for the TMF spectral data are extremely effective in canceling the strong solar Fraunhofer lines which interfere with terrestrial $\mathrm{OH}$ absorption measurements. All of the $\mathrm{OH}$ column measurements are subject to systematic uncertainties. Some, such as the uncertainties on the oscillator strengths for the $\mathrm{OH}$ lines used for the column observations, are the same for all of the measurement sites. Others, such as corrections for stray light, will differ for each site. To minimize the influence of possible systematic errors, the analysis in this paper will focus on normalized deviations of the $\mathrm{OH}$ column from the average observed over TMF. Time-dependent modeling of the diurnal variation and the absolute $\mathrm{OH}$ column abundance are underway and will be published when completed.

[7] The goals for this paper are to characterize the first 3.5 years of the TMF OH column measurements and assess how well model calculations can reproduce the observed, statistically significant variations in the $\mathrm{OH}$ column. Observed intra-annual variations in $\mathrm{O}_{3}$ and $\mathrm{H}_{2} \mathrm{O}$ in the stratosphere and mesosphere derived from measurements by the Halogen Occultation Experiment (HALOE) [Russell et al., 1993] on the Upper Atmosphere Research Satellite (UARS) will be used to calculate expected intra-annual variations in the $\mathrm{OH}$ column abundance. These calculations are then compared to the observed intra-annual variations in the $\mathrm{OH}$ column.

[8] Section 2 briefly describes the $\mathrm{OH}$ column measurements made over TMF. Section 3 presents our analysis of intra-annual variations in the OH column over TMF. Section 4 describes the analytic photochemical model, and section 5 how it was used to derive sensitivity coefficients for the primary geophysical parameters governing the $\mathrm{OH}$ column abundance in models: $\mathrm{H}_{2} \mathrm{O}$ and $\mathrm{O}_{3}$ concentrations. The sensitivity coefficients quantitatively derived from the analytic model relate variations in $\mathrm{H}_{2} \mathrm{O}$ and $\mathrm{O}_{3}$ concentrations to the predicted effect on the $\mathrm{OH}$ column abundance. Section 6 uses these sensitivity coefficients to compare the observed variations in the $\mathrm{OH}$ column over TMF with predictions based on observed variations in $\mathrm{H}_{2} \mathrm{O}$ and $\mathrm{O}_{3}$ concentrations near TMF.

\section{Observations}

[9] Since July 1997, the OH column abundance has been measured over TMF using the Fourier transform ultraviolet spectrometer (FTUVS) [Cageao et al., 2001; Mills et al., 2002]. Figure A1 in the auxiliary material ${ }^{1}$ shows the dates

\footnotetext{
${ }^{1}$ Auxiliary material is available via Web browser or via Anonymous FTP from ftp://agu.org/apend/jd/2003JD003481/. Information on searching and submitting electronic supplements is found at http://www.agu.org/pubs/ esupp_about.html.
} 
and solar zenith angles (SZA) for morning measurements. Afternoon data coverage is similar, Figure A2. The collecting optics for the FTUVS were upgraded in SeptemberDecember 1999 so no data were collected during this period.

[10] The FTUVS acquires spectra of the Sun from the ground by viewing the east and west limbs of the Sun, alternately, for $15 \mathrm{~min}$ each. The Doppler shift induced by the rotation of the Sun shifts the solar Fraunhofer lines observed at the east and west limbs of the Sun relative to the telluric $\mathrm{OH}$ lines. A properly shifted ratio of a pair of east and west limb spectra then removes the solar Fraunhofer lines and leaves only features due to the telluric $\mathrm{OH}$. The $\mathrm{OH}$ features are fit with a calculated spectrum to derive the line-of-sight $\mathrm{OH}$ column abundance. The calculated spectrum includes a model of the instrument line shape and the expected Doppler broadening based on a standard atmospheric temperature profile. The line-of-sight $\mathrm{OH}$ column abundance is divided by $\cos (\mathrm{SZA})$ to determine the vertical $\mathrm{OH}$ column abundance [Cageao et al., 2001]. The FTUVS at TMF has an unapodized spectral resolving power near 500,000 and integration time of $30 \mathrm{~min}$ for a pair of east and west solar limb spectra [Cageao et al., 2001]. The measured absorption is converted to $\mathrm{OH}$ column abundance using the oscillator strengths for the individual rotational lines in the $\mathrm{A}^{2} \Sigma^{+} \leftarrow \mathrm{X}^{2} \Pi(0,0)$ band for $\mathrm{OH}$ [Cageao et al., 1997]. The band oscillator strength used in the present analysis is within $0.5 \%$ of those used by other groups [Burnett and Burnett, 1981; Iwagami et al., 1995]. The $\mathrm{OH}$ lines observed by the FTUVS are optically thin (total column absorption $\sim 1 \%$ ) so the measurements are sensitive to the entire $\mathrm{OH}$ column.

[11] At least seven $\mathrm{OH}$ lines in the $\mathrm{A}^{2} \Sigma^{+} \leftarrow \mathrm{X}^{2} \Pi(0,0)$ band are observed. This paper focuses on results from the $\mathrm{P}_{1}(1)$ line $\left(32440.5741 \mathrm{~cm}^{-1}\right)$ and the $\mathrm{Q}_{1}(2)$ line $\left(32458.5918 \mathrm{~cm}^{-1}\right)$ [Stark et al., 1994]. The $\mathrm{P}_{1}(1)$ line was used by other groups because the solar spectrum has less curvature near the $\mathrm{P}_{1}(1)$ line and it gave the most reliable ("stable") results [Iwagami et al., 1995; Notholt et al., 1997]. Observations of the $Q_{1}(2)$ line have not been reported by previous investigators. The TMF annual averages derived from the $\mathrm{P}_{1}(1)$ and $\mathrm{Q}_{1}(2)$ lines agree [Mills et al., 2002]. The other five $\mathrm{OH}$ lines observed at TMF are weaker and have greater interference from solar lines. Reliable retrieval techniques using the weaker lines are still being developed and were not included in the present analysis.

[12] Figures A3 and A4 summarize all of the measurements of $\mathrm{OH}$ column abundance that were made over TMF from July 1997 to December 2001. A strong, approximately linear dependence on SZA is present in the TMF data, as has been reported for other data sets [Burnett and Burnett, 1981]. The range of observable SZAs for each season is indicated by the symbols, and Figure A3 indicates the variability within each season is comparable in magnitude to that between seasons at any given SZA.

[13] The primary source of uncertainty in the measured $\mathrm{OH}$ column is the spectral fit [Cageao et al., 2001]. Figure A5 is a histogram of the $2 \sigma_{s f}$ spectral fit uncertainty for $\mathrm{P}_{1}(1)$ data collected after June 1997. Figure A6 shows the spectral fit uncertainties for $\mathrm{Q}_{1}(2)$ data. The median spectral fit uncertainty $\left(2 \sigma_{s f}\right)$ for $\mathrm{P}_{1}(1)$ data is $14 \%$ and for $\mathrm{Q}_{1}(2)$ data is $17 \%$. The $2 \sigma_{r o}$ random uncertainty from all other sources (root-sum-square) is 14\% [Cageao et al., 2001], and the median of the total (root-sum-square) random uncertainty $\left(2 \sigma_{r}\right)$ is $20 \%$. The $2 \sigma_{s}$ systematic uncertainty from all sources (root-sum-square) is estimated to be $12 \%$ [Cageao et al., 2001].

\section{Measurement Results}

[14] The $\mathrm{OH}$ column abundance observed over TMF (Figures A3 and A4) is a strong function of solar zenith angle (SZA) but statistically significant variations are observed at all SZA. To characterize the observed variations and minimize the susceptibility to systematic uncertainties [Mills et al., 2002], the typical solar zenith angle dependence must be removed. This has been accomplished by calculating linear least squares fits, separately, for the morning and afternoon measurements (Figures 1 and A7). The measured $\mathrm{OH}$ column abundances are then divided by the appropriate empirical fit. Hereinafter, the resultant fractional deviations from the empirical fits are referred to as "normalized OH column abundances."

[15] Figures 1 and A7 have two different empirical fits. The linear fit was calculated for $10^{\circ}-65^{\circ}$ solar zenith angle where the spectra have the best signal-to-noise ratio so the measured $\mathrm{OH}$ columns have the best quality. The secondorder polynomial fit was calculated for $10^{\circ}-85^{\circ}$ solar zenith angle. The two fits agree to within the uncertainty on the linear fit for most of the $10^{\circ}-65^{\circ}$ solar zenith angle range, so a higher-order fit is not justified and we believe the linear fit adequately describes the overall TMF data set for $10^{\circ}-$ $65^{\circ}$ solar zenith angle even though model calculations [Canty et al., 2000] predict a non-linear relationship between $\mathrm{OH}$ column and solar zenith angle. The best linear fits for the $\mathrm{P}_{1}(1) \mathrm{OH}$ column measurements over TMF for July 1997 to December 2001 at $10^{\circ}-65^{\circ} \mathrm{SZA}$ with spectral fit uncertainty $\leq 36 \%$ are given by equations (1) and (2).

$$
\begin{aligned}
& \mathrm{m}_{1}=-5.87( \pm 0.29) 10^{11} \times \mathrm{SZA}+7.60( \pm 0.14) 10^{13} \\
& \mathrm{a}_{1}=-4.63( \pm 0.32) 10^{11} \times \mathrm{SZA}+7.38( \pm 0.16) 10^{13}
\end{aligned}
$$

where SZA $=$ solar zenith angle, $\mathrm{m}_{1}=$ morning $\mathrm{P}_{1}(1) \mathrm{OH}$ column $\left(\mathrm{cm}^{-2}\right)$, and $\mathrm{a}_{1}=$ afternoon $\mathrm{P}_{1}(1) \mathrm{OH}$ column $\left(\mathrm{cm}^{-2}\right)$. The best linear least squares fits for the $\mathrm{Q}_{1}(2) \mathrm{OH}$ column measurements over TMF for July 1997 to December 2001 at $10^{\circ}-65^{\circ} \mathrm{SZA}$ with spectral fit uncertainty $\leq 41 \%$ (Figures A 8 and A9) are given by equations (3) and (4).

$$
\begin{aligned}
& \mathrm{m}_{0}=-6.32( \pm 0.35) 10^{11} \times \mathrm{SZA}+8.15( \pm 0.17) 10^{13} \\
& \mathrm{a}_{0}=-5.60( \pm 0.39) 10^{11} \times \mathrm{SZA}+8.31( \pm 0.19) 10^{13}
\end{aligned}
$$

where $\mathrm{m}_{0}=$ morning $\mathrm{Q}_{1}(2) \mathrm{OH}$ column $\left(\mathrm{cm}^{-2}\right)$, and $\mathrm{a}_{0}=$ afternoon $\mathrm{Q}_{1}(2) \mathrm{OH}$ column $\left(\mathrm{cm}^{-2}\right)$. The annual average $\mathrm{OH}$ column derived from observations of the $\mathrm{P}_{1}(1)$ and $\mathrm{Q}_{1}(2) \mathrm{OH}$ lines (as described by $\mathrm{m}_{1}, \mathrm{a}_{1}, \mathrm{~m}_{0}$, and $\mathrm{a}_{0}$ ) agree to within their mutual uncertainties [Mills et al., 2002], and the recently revised line strengths for the two $\mathrm{OH}$ lines [Gillis et al., 2001] are expected to improve the agreement of these 


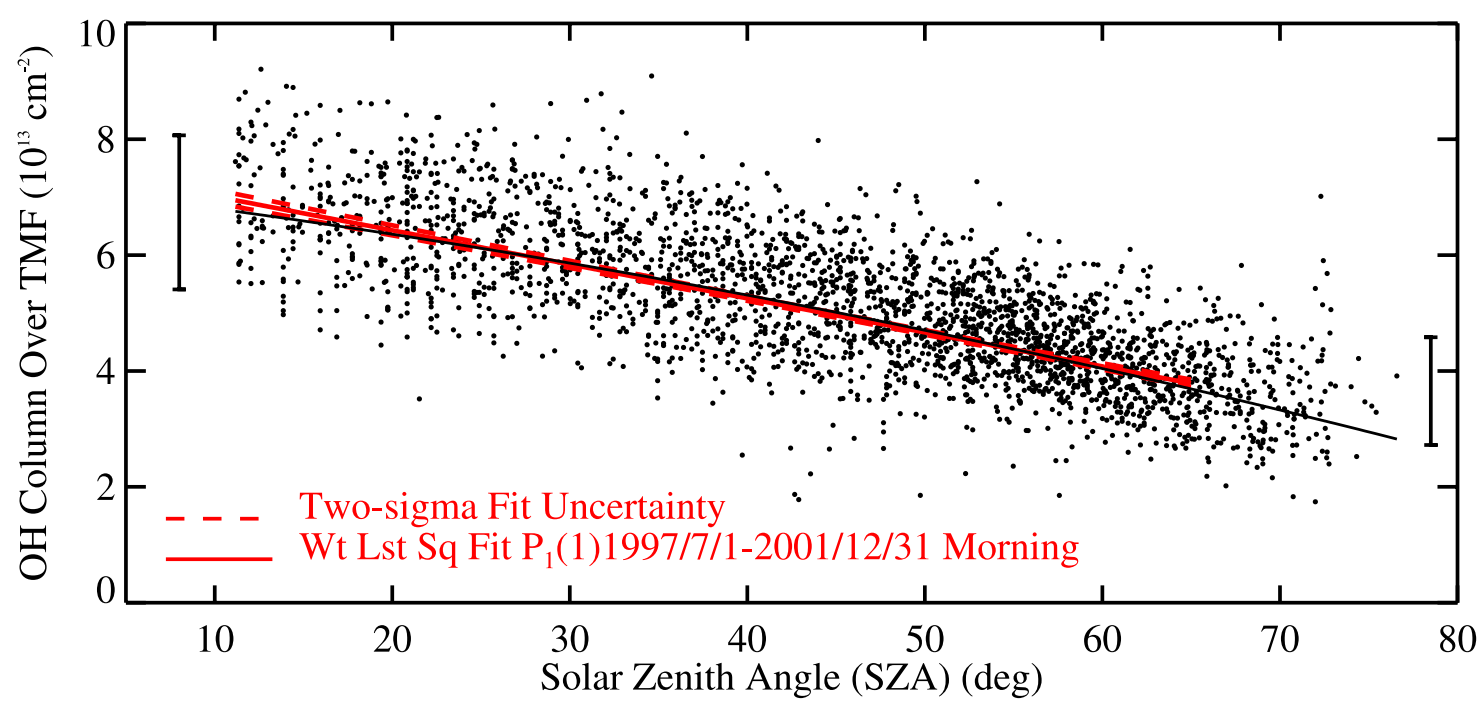

Figure 1. Morning $\mathrm{OH}$ column measurements with spectral fit uncertainty smaller than $36 \%$ as a function of SZA over TMF for July 1997 to December 2001 for the $\mathrm{P}_{1}(1) \mathrm{OH}$ line. Each point on the plot is one measurement of the $\mathrm{OH}$ column abundance as derived from a pair of 15-min integrations on each limb of the Sun. The vertical bars at each end illustrate the typical $2 \sigma_{r}$ random uncertainty for an $\mathrm{OH}$ column measurement at $10^{\circ}-20^{\circ}$ and $65^{\circ}-75^{\circ} \mathrm{SZA}$, respectively. Points and vertical bars are the same as in Figure A3, but excluding points with large spectral fit uncertainties. The solid black curve is the best second-order fit to the data. The solid red line is the best linear fit to the data. The short-dashed red lines are the $2 \sigma$ uncertainties on the best linear fit. All fits and the uncertainties on the fits were calculated via a weighted least squares singular value decomposition technique [Press et al., 1989, chapter 14]. The second-order and linear fits are almost indistinguishable for most SZA. The smallest $\mathrm{OH}$ column abundances at $25^{\circ}-65^{\circ} \mathrm{SZA}$ in this figure were measured after a solar storm in April 2000, but the spectral fit uncertainties for the $\mathrm{OH}$ column abundances measured after the April 2000 solar storm (Figure A3) are generally larger than the 36\% limit used to select data for inclusion in this figure.

annual averages by about $2-3 \%$. The shallower slope for the fit to the afternoon $\mathrm{OH}$ column (when compared to the morning $\mathrm{OH}$ column) is true for almost all months for both the $\mathrm{P}_{1}(1)$ and $\mathrm{Q}_{1}(2)$ lines.

[16] Deviations from the empirical fits shown in Figures 1 and A7 are believed to be primarily due to geophysical variations in the atmosphere. To facilitate detection of variability patterns on timescales longer than 1 day and to enable comparison with model calculations, the normalized $\mathrm{P}_{1}$ (1) $\mathrm{OH}$ column abundances were averaged to create morning and afternoon daily averages (Figure A10). Statistically significant deviations from the empirical mean of up to $+40 \%$ and $-50 \%$ are observed and variability on at least week-to-week or monthly timescales is readily apparent.

[17] Inspection of the normalized $\mathrm{P}_{1}(1) \mathrm{OH}$ column abundances showed no obvious dependence on solar zenith angle, and correlation tests among the normalized $\mathrm{P}_{1}(1) \mathrm{OH}$ abundances for most solar zenith angles showed high correlations. The morning and afternoon daily average normalized $\mathrm{P}_{1}(1) \mathrm{OH}$ columns also are highly correlated (Figure 2), with a slope near unity and an intercept near zero (equation (5)).

$$
\mathrm{a}_{1 n}=0.95( \pm 0.06) \mathrm{m}_{1 n}+0.01( \pm 0.01)
$$

where $\mathrm{a}_{1 n}=$ daily average normalized afternoon $\mathrm{P}_{1}(1) \mathrm{OH}$ column abundance and $\mathrm{m}_{1 n}=$ daily average normalized morning $\mathrm{P}_{1}(1) \mathrm{OH}$ column abundance. The only $\mathrm{P}_{1}(1)$ data with a lower degree of correlation than is shown in Figure 2 are data collected at $\gtrsim 50^{\circ}$ solar zenith angle in the morning. Morning data collected at solar zenith angles $\geq 45^{\circ}$ over FPO have been the subject of several studies [Burnett and Minschwaner, 1998]. For the TMF data set, however, these early morning data have the lowest signal-to-noise ratios because they have the longest slant paths through the atmosphere and the $\mathrm{OH}$ column abundance is smallest. (Broadband atmospheric attenuation, such as Rayleigh scattering, and $\mathrm{O}_{3}$ absorption near $308 \mathrm{~nm}$ is largest at the longest slant paths.) Thus the early morning data have the poorest quality spectral fits. On the basis of the lack of a clear temporal pattern in Figure A11, we believe that the lower degree of correlation between early morning TMF data and TMF data collected throughout the remainder of the day is due to the poorer quality of the early morning measurements.

[18] The high degree of correlation observed among $\mathrm{OH}$ column variations at all solar zenith angles and between morning and afternoon strongly suggest that the observed variations are not random fluctuations. These results also indicate the daily average normalized $\mathrm{P}_{1}(1) \mathrm{OH}$ column abundances adequately capture the variability in the measured $\mathrm{P}_{1}(1) \mathrm{OH}$ column abundances and suggest that the observed changes in the normalized $\mathrm{P}_{1}(1) \mathrm{OH}$ column occur "uniformly" throughout the day. On the basis of the high correlation between the morning and afternoon averages for the $\mathrm{P}_{1}(1) \mathrm{OH}$ line measurements, the normalized $\mathrm{OH}$ columns from the entire day have been averaged (Figure 3). A statistically significant increase in the $\mathrm{OH}$ 


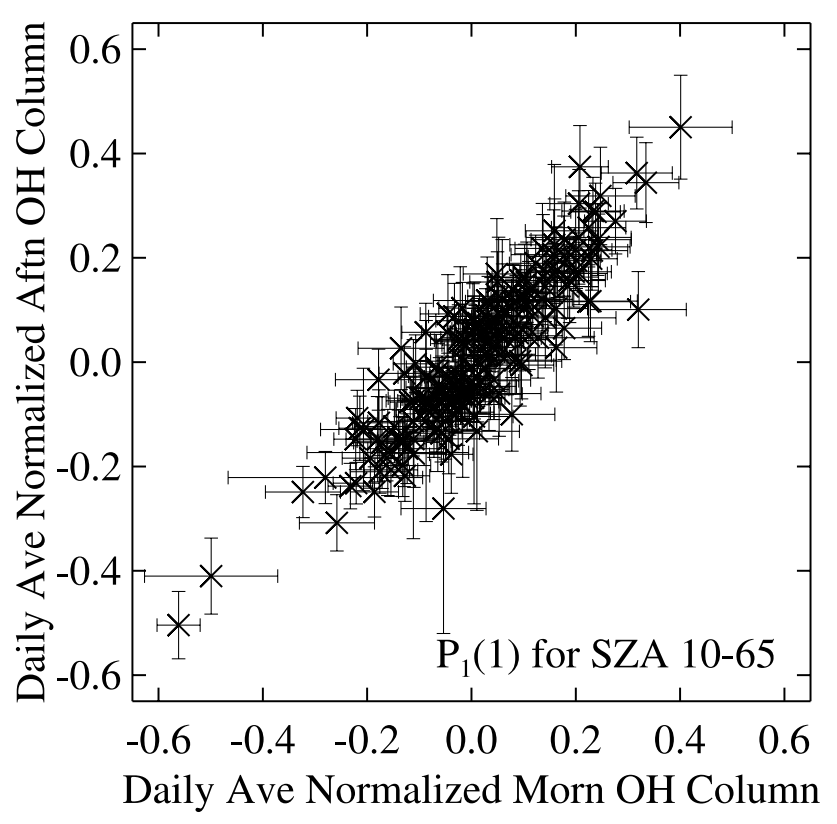

Figure 2. Scatterplot of the morning and afternoon 1-day averages (Figure A10), showing the high degree of correlation between the 1-day average normalized $\mathrm{OH}$ column abundance measured in the morning and afternoon. The horizontal axis is the average for each day of the normalized morning $\mathrm{OH}$ column abundance for the $\mathrm{P}_{1}(1)$ $\mathrm{OH}$ line data collected at $10^{\circ}-65^{\circ}$ SZA between July 1997 and December 2001. The vertical axis is the average for each day of the normalized afternoon $\mathrm{OH}$ column abundance for the same conditions. Uncertainties are $2 \sigma_{r}$ uncertainties on the mean for each day [Bevington, 1969, chapter 5]. The weighted linear least squares fit through the measurements [Press et al., 1989, chapter 14] is described by $a_{1 n}=(0.95 \pm 0.06) * m_{1 n}+(0.01 \pm 0.01)$, where $a_{1 n}$ is the normalized afternoon $\mathrm{OH}$ column and $m_{1 n}$ is the normalized morning $\mathrm{OH}$ column. column abundance over TMF from 1997 to 2001 is evident and the linear fit shown in Figure 3 indicates the $\mathrm{OH}$ column abundance over TMF increased by about $25 \%$ (difference divided by mean) from July 1997 to December 2001. The smallest $\mathrm{OH}$ column abundances were recorded during one week periods in April and July 2000, shortly after intense solar storms. The standard deviation for the intra-annual variation in the daily average normalized $\mathrm{P}_{1}(1)$ $\mathrm{OH}$ column abundance over TMF after subtracting the linear fit to the interannual trend is about 0.12 and the peak-to-peak amplitude of the daily average variation is $\sim 30-35 \%$.

[19] The morning and afternoon daily average normalized $\mathrm{Q}_{1}(2) \mathrm{OH}$ column abundances also are highly correlated (Figure A12), but the correlation is not as good as for the $\mathrm{P}_{1}(1) \mathrm{OH}$ line and the slope for the fit relating the morning and afternoon daily averages (equation (6)) differs from 1.0 by a statistically significant amount.

$$
\mathrm{a}_{0 n}=0.80( \pm 0.07) \mathrm{m}_{0 n}+0.00( \pm 0.01)
$$

where $\mathrm{a}_{0 n}=$ daily average normalized afternoon $\mathrm{Q}_{1}(2) \mathrm{OH}$ column abundance and $\mathrm{m}_{0 n}=$ daily average normalized morning $\mathrm{Q}_{1}(2) \mathrm{OH}$ column abundance. There is a correlation between the daily average normalized $\mathrm{OH}$ columns from the $\mathrm{P}_{1}(1)$ and $\mathrm{Q}_{1}(2) \mathrm{OH}$ lines (Figure A13), but the slope for the fit relating the $\mathrm{P}_{1}(1)$ and $\mathrm{Q}_{1}(2)$ results (equation (7)) differs from 1.0 by a statistically significant amount.

$$
\mathrm{d}_{0 n}=0.82( \pm 0.04) \mathrm{d}_{1 n}+0.00( \pm 0.01)
$$

where $\mathrm{d}_{1 n}=\mathrm{P}_{1}(1)$ daily average normalized $\mathrm{OH}$ column and $\mathrm{d}_{0 n}=\mathrm{Q}_{1}(2)$ daily average normalized $\mathrm{OH}$ column. This indicates the deviations from the mean for the $\mathrm{Q}_{1}(2) \mathrm{OH}$ line are typically only $82 \%$ of those for the $\mathrm{P}_{1}(1) \mathrm{OH}$ line.

[20] The differences between the results from the $\mathrm{P}_{1}(1)$ and $\mathrm{Q}_{1}(2)$ lines can be partially attributed to differences in removing the background solar Fraunhofer spectrum, but other possible sources for the observed differences are still

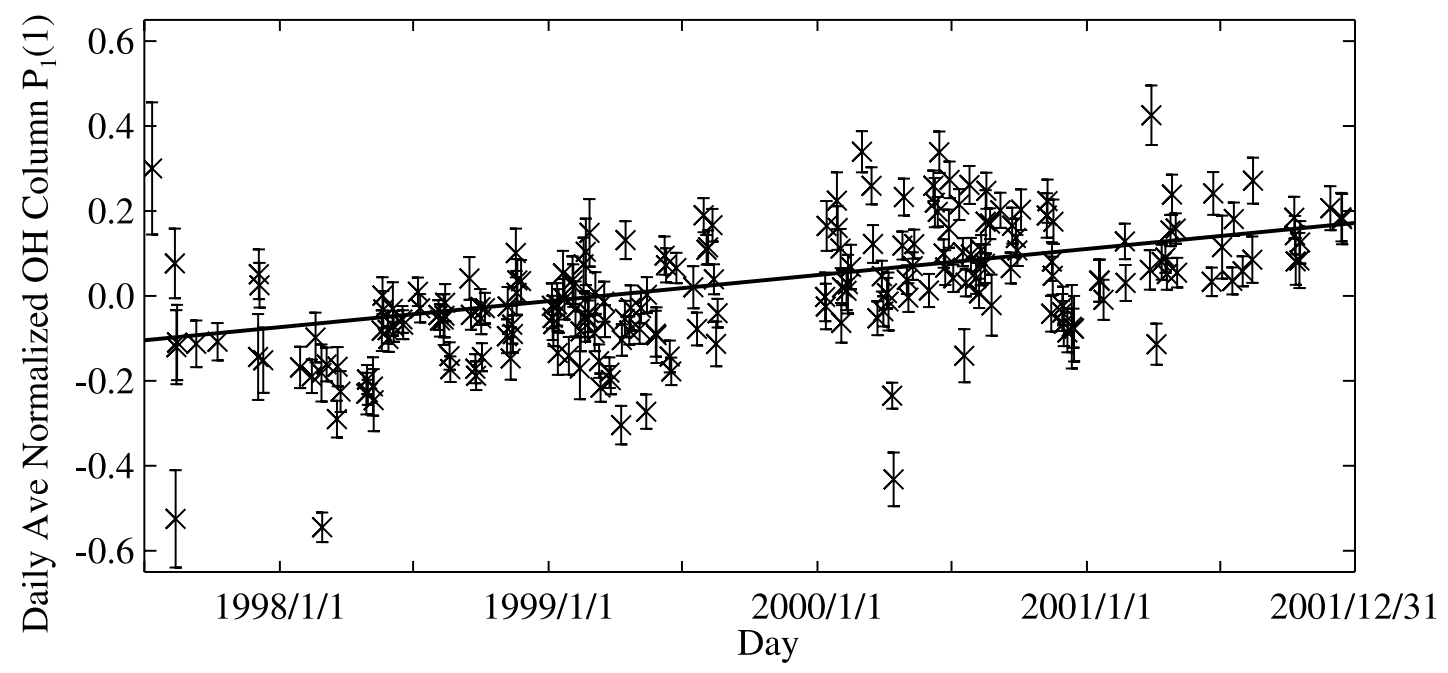

Figure 3. Daily average of normalized $\mathrm{OH}$ column measurements over TMF for the $\mathrm{P}_{1}(1) \mathrm{OH}$ line at $10^{\circ}-65^{\circ} \mathrm{SZA}$. Uncertainties are $2 \sigma_{r}$ uncertainties on the mean for each day. The line indicates a linear least squares fit to the data. 
under review. On the basis of the known difficulties in properly removing the background solar Fraunhofer spectrum from the $Q_{1}(2)$ line measurements and the statistical analyses described above, the $\mathrm{Q}_{1}(2)$ line measurements have not been used in the modeling portion of the present study. The recently revised line strengths [Gillis et al., 2001] should not significantly alter the normalized $\mathrm{OH}$ column abundances.

\section{Photochemical Models}

[21] Two photochemical models were used to interpret the intra-annual variations observed in the $\mathrm{OH}$ column over TMF: The Caltech/JPL numerical model [Allen et al., 1981] and an analytic model [Pickett and Peterson, 1996]. The numerical model provided estimates of the expected photochemical state of the atmosphere at selected solar zenith angles and the analytic model was used for sensitivity (perturbation) calculations about the numerical model results. The analytic model was more convenient for the sensitivity calculations than the numerical model because the analytic model does not incorporate the automated feedback processes that are present in the numerical model. Thus each of the parameters affecting $\mathrm{OH}$ concentrations could be varied independently.

[22] The numerical model was initialized using species profiles measured by the Atmosphere Trace Molecule Spectroscopy (ATMOS) Experiment in 1985 [Allen and Delitsky, 1991]. The one-dimensional numerical model was run to diurnally averaged steady state with vertical eddy diffusion, then run in a diurnally varying mode with no transport until the $\mathrm{OH}$ concentrations at all model levels between 0 and $84 \mathrm{~km}$ altitude were diurnally repetitive to within $0.5 \%$. The kinetic rates and photolysis cross sections [DeMore et al., 1997], transmission and absorption in the $\mathrm{O}_{2}$ Schumann-Runge Band [Allen and Frederick, 1982; Froidevaux et al., 1985], and the solar fluxes [Allen and Delitsky, 1991] were standard values and parameterizations for the Caltech/JPL model. The curvature of the Earth's atmosphere and local sunrise/sunset were accounted for in determining the photolysis rates at each altitude. Recently recommended changes in kinetic rates [Sander et al., 2000] do not have a significant impact on the present calculations (section 5).

[23] The analytic photochemical model used for the present study was based on that developed by Pickett and Peterson [1996]. The primary assumptions are the same as for their model: (1) $\mathrm{OH}, \mathrm{H}$, and $\mathrm{HO}_{2}$ are in photochemical steady state, (2) $\mathrm{HNO}_{3}$ is in photochemical steady state, (3) $\mathrm{O}\left({ }^{3} \mathrm{P}\right)$ and $\mathrm{O}\left({ }^{1} \mathrm{D}\right)$ are in photochemical steady state, and (4) each $\mathrm{CH}_{3}$ radical produced is assumed to give a net yield of one $\mathrm{HO}_{2}$ from subsequent (unmodeled) reactions. The analytic model includes no vertical transport. The nominal concentrations (except that for $\mathrm{OH}$ ), kinetic reaction rates, and photolysis rates at all altitudes were taken from the numerical model. The analytic model assumes production of $\mathrm{HO}_{x}\left(=\mathrm{H}+\mathrm{OH}+\mathrm{HO}_{2}\right)$ is dominated by photolysis of $\mathrm{H}_{2} \mathrm{O}$ and reactions of $\mathrm{O}\left({ }^{1} \mathrm{D}\right)$ with $\mathrm{H}_{2} \mathrm{O}$ and $\mathrm{CH}_{4}$. Loss of $\mathrm{HO}_{x}$ is assumed to be dominated by reaction of $\mathrm{OH}$ with $\mathrm{HO}_{2}$. Reactions of $\mathrm{OH}$ with $\mathrm{NO}_{2}$ to form $\mathrm{HNO}_{3}$ and of $\mathrm{OH}$ with $\mathrm{HNO}_{3}$ were also included. The photolysis and kinetic reactions included in the analytic model are given in
Table 1. Reactions for the Analytic OH Model

\begin{tabular}{|c|c|c|c|c|c|c|c|c|c|}
\hline \multicolumn{9}{|c|}{ Reaction } & \multirow{2}{*}{$\frac{\text { Rate Constant }^{\mathrm{a}}}{J_{1 a}}$} \\
\hline $\mathrm{O}_{3}$ & + & $\mathrm{h} \nu$ & & & $\rightarrow$ & & $\mathrm{O}\left({ }^{1} \mathrm{D}\right)$ & $+\mathrm{O}_{2}\left({ }^{1} \Delta\right)$ & \\
\hline $\mathrm{O}_{3}$ & + & $\mathrm{h} v$ & & & $\rightarrow$ & & $O\left({ }^{1} D\right)$ & $+\mathrm{O}_{2}$ & $J_{1 b}$ \\
\hline $\mathrm{O}_{3}$ & + & $\mathrm{h} \nu$ & & & $\rightarrow$ & & $\mathrm{O}$ & $+\mathrm{O}_{2}$ & $J_{2}$ \\
\hline $\mathrm{H}_{2} \mathrm{O}$ & + & $\mathrm{h} \nu$ & & & $\rightarrow$ & & $\mathrm{OH}$ & $+\mathrm{H}^{2}$ & $J_{3}$ \\
\hline $\mathrm{HNO}_{3}$ & + & $\mathrm{h} \nu$ & & & $\rightarrow$ & & $\mathrm{OH}$ & $+\mathrm{NO}_{2}$ & $J_{4}$ \\
\hline $\mathrm{O}\left({ }^{1} \mathrm{D}\right)$ & + & $\mathrm{N}_{2}$ & & & $\rightarrow$ & & $\mathrm{O}$ & $+\mathrm{N}_{2}$ & $k_{1 a}$ \\
\hline $\mathrm{O}\left({ }^{1} \mathrm{D}\right)$ & + & $\mathrm{O}_{2}$ & & & $\rightarrow$ & & $\mathrm{O}$ & $+\mathrm{O}_{2}$ & $k_{1 b}$ \\
\hline $\mathrm{O}\left({ }^{1} \mathrm{D}\right)$ & + & $\mathrm{H}_{2} \mathrm{O}$ & & & $\rightarrow$ & 2 & $\mathrm{OH}$ & & $k_{2}$ \\
\hline $\mathrm{OH}$ & + & $\mathrm{HO}_{2}$ & & & $\rightarrow$ & & $\mathrm{H}_{2} \mathrm{O}$ & $+\mathrm{O}_{2}$ & $k_{3}$ \\
\hline $\mathrm{O}$ & + & $\mathrm{O}_{2}$ & + & $\mathrm{N}$ & $\rightarrow$ & & $\mathrm{O}_{3}$ & $+\mathrm{N}_{2}$ & $k_{4 a}$ \\
\hline $\mathrm{O}$ & + & $\mathrm{O}_{2}$ & + & $\mathrm{O}$ & $\rightarrow$ & & $\mathrm{O}_{3}$ & $+\mathrm{O}_{2}$ & $k_{4 b}$ \\
\hline $\mathrm{OH}$ & + & $\mathrm{O}$ & & & $\rightarrow$ & & $\mathrm{H}$ & $+\mathrm{O}_{2}$ & $k_{5}$ \\
\hline $\mathrm{OH}$ & + & $\mathrm{O}_{3}$ & & & $\rightarrow$ & & $\mathrm{O}_{2}$ & $+\mathrm{HO}_{2}$ & $k_{6}$ \\
\hline $\mathrm{OH}$ & + & $\mathrm{CO}$ & & & $\rightarrow$ & & $\mathrm{H}$ & $+\mathrm{CO}_{2}$ & $k_{7}$ \\
\hline $\mathrm{HO}_{2}$ & + & $\mathrm{O}$ & & & $\rightarrow$ & & $\mathrm{OH}$ & $+\mathrm{O}_{2}$ & $k_{8}$ \\
\hline $\mathrm{HO}_{2}$ & + & $\mathrm{O}_{3}$ & & & $\rightarrow$ & & $\mathrm{OH}$ & $+2 \mathrm{O}_{2}$ & $k_{9}$ \\
\hline $\mathrm{HO}_{2}$ & + & $\mathrm{NO}$ & & & $\rightarrow$ & & $\mathrm{OH}$ & $+\mathrm{NO}_{2}$ & $k_{10}$ \\
\hline $\mathrm{OH}$ & + & $\mathrm{HNO}_{3}$ & & & $\rightarrow$ & & $\mathrm{H}_{2} \mathrm{O}$ & $+\mathrm{NO}_{3}$ & $k_{11}$ \\
\hline $\mathrm{H}$ & + & $\mathrm{O}_{3}$ & & & $\rightarrow$ & & $\mathrm{OH}$ & $+\mathrm{O}_{2}$ & $k_{12}$ \\
\hline $\mathrm{H}$ & + & $\mathrm{O}_{2}$ & + & $\mathrm{M}$ & $\rightarrow$ & & $\mathrm{HO}_{2}$ & $+\mathrm{M}$ & $k_{13}$ \\
\hline $\mathrm{OH}$ & + & $\mathrm{NO}_{2}$ & + & $\mathrm{M}$ & $\rightarrow$ & & $\mathrm{HNO}_{3}$ & $+\mathrm{M}$ & $k_{14}$ \\
\hline $\mathrm{O}\left({ }^{1} \mathrm{D}\right)$ & + & $\mathrm{CH}_{4}$ & & & $\rightarrow^{\mathrm{b}}$ & & $\mathrm{OH}$ & $+\mathrm{CH}_{3}$ & $k_{15}$ \\
\hline $\mathrm{OH}$ & + & $\mathrm{CH}_{4}$ & & & $\rightarrow^{\mathrm{b}}$ & & $\mathrm{H}_{2} \mathrm{O}$ & $+\mathrm{CH}_{3}$ & $k_{16}$ \\
\hline
\end{tabular}

${ }^{\mathrm{a}}$ Reaction numbering system is same as that used by Pickett and Peterson [1996].

${ }^{\mathrm{b}} \mathrm{A}$ net yield of one $\mathrm{HO}_{2}$ per $\mathrm{CH}_{3}$ radical produced was assumed, as was done by Pickett and Peterson [1996].

Table 1. The reaction numbering system used by Pickett and Peterson [1996] has been adopted for the present analytic model. The analytic model's absolute $\mathrm{OH}$ concentrations agreed well ( $\leq 5 \%$ difference) with those from the numerical model at $30-60 \mathrm{~km}$ altitude at all three solar zenith angles that were used for the sensitivity analyses (morning $60^{\circ}$, noon, and afternoon $65^{\circ}$ ). At noon, the analytic model's absolute $\mathrm{OH}$ concentrations were within $5 \%$ of the numerical model's at $25-70 \mathrm{~km}$ altitude. Differential calculations, such as those used in section 6 , should agree even more closely for the two photochemical models at $25-70 \mathrm{~km}$ altitude where $65-70 \%$ of the $\mathrm{OH}$ column lies.

[24] The present analytic model differs in three ways from the Pickett and Peterson [1996] model. First, the spinforbidden channel for $\mathrm{O}_{3}$ photolysis was included, photolysis reaction $1 \mathrm{~b}$. Second, the different efficiencies for $\mathrm{N}_{2}$ and $\mathrm{O}_{2}$ as third bodies were included for kinetic reactions 1 and 4. Third, kinetic reaction 1 was included properly as a source of $\mathrm{O}\left({ }^{3} \mathrm{P}\right)$ atoms. Equation (2) of Pickett and Peterson [1996] is therefore modified to be

$$
[\mathrm{O}]=\frac{\left(J_{1 a}+J_{1 b}+J_{2}\right)\left[\mathrm{O}_{3}\right]}{\left(k_{4 a}\left[N_{2}\right]+k_{4 b}\left[\mathrm{O}_{2}\right]\right)\left[\mathrm{O}_{2}\right]}
$$

None of the subsequent equations in Pickett and Peterson [1996] are affected by this correction, but the $\mathrm{O}$ and $\mathrm{OH}$ concentrations from the present model will differ by a small amount from those calculated using the Pickett and Peterson [1996] model.

[25] For the assumptions stated above, the $\mathrm{OH}$ concentration is determined by finding the positive root of equation (9) [Pickett and Peterson, 1996]. Solutions for this equation were computed numerically.

$$
\alpha[\mathrm{OH}]^{2}+\beta[\mathrm{OH}]+\gamma=0
$$


where

$$
\begin{gathered}
\alpha=\frac{k_{3} c_{2}}{c_{1}} \\
\beta=k_{11}\left[\mathrm{HNO}_{3}\right]-\frac{k_{3} c_{3}}{c_{1}}\left[\mathrm{H}_{2} \mathrm{O}\right] \\
\gamma=-\left(J_{3}+\frac{\left(J_{1 a}+J_{1 b}\right) k_{2}\left[\mathrm{O}_{3}\right]}{\left(k_{1 a}\left[\mathrm{~N}_{2}\right]+k_{1 b}\left[\mathrm{O}_{2}\right]\right)}\right)\left[\mathrm{H}_{2} \mathrm{O}\right]-\frac{\left(J_{1 a}+J_{1 b}\right) k_{15}\left[\mathrm{O}_{3}\right]\left[\mathrm{CH}_{4}\right]}{\left(k_{1 a}\left[\mathrm{~N}_{2}\right]+k_{1 b}\left[\mathrm{O}_{2}\right]\right)} \\
c_{1}=\frac{k_{8}\left(J_{1 a}+J_{1 b}+J_{2}\right)\left[\mathrm{O}_{3}\right]}{\left(k_{4 a}\left[\mathrm{~N}_{2}\right]+k_{4 b}\left[\mathrm{O}_{2}\right]\right)\left[\mathrm{O}_{2}\right]}-k_{9}\left[\mathrm{O}_{3}\right]+k_{10}[\mathrm{NO}] \\
c_{2}=k_{6}\left[\mathrm{O}_{3}\right]+\frac{f k_{5}\left(J_{1 a}+J_{1 b}+J_{2}\right)\left[\mathrm{O}_{3}\right]}{\left(k_{4 a}\left[\mathrm{~N}_{2}\right]+k_{4 b}\left[\mathrm{O}_{2}\right]\right)\left[\mathrm{O}_{2}\right]} \\
+f k_{7}[\mathrm{CO}]+k_{16}\left[\mathrm{CH}_{4}\right]+k_{11}\left[\mathrm{HNO}_{3}\right] \\
c_{3}=(1-f) J_{3}+\frac{k_{2}\left(J_{1 a}+J_{1 b}\right)\left[\mathrm{O}_{3}\right]}{\left(k_{1 a}\left[\mathrm{~N}_{2}\right]+k_{1 b}\left[\mathrm{O}_{2}\right]\right)} \\
f=\frac{k_{13}\left[\mathrm{O}_{2}\right][M]}{k_{12}\left[\mathrm{O}_{3}\right]+k_{13}\left[\mathrm{O}_{2}\right][M]}
\end{gathered}
$$

[26] Simplified approximations to the full solution for equation (9), such as equations (17), (18), and (19), help in understanding the physical quantities that control $\mathrm{OH}$ concentrations in different regions of the atmosphere. Equations (17), (18), and (19) were derived from the full analytic model by retaining only the largest term(s) in the solution at the specified altitudes. The two largest terms were retained if the difference between them was less than a factor of 3 .

$$
\begin{gathered}
{[\mathrm{OH}](30-35 \mathrm{~km}) \approx} \\
\sqrt{\left(\frac{k_{2} J_{1 a}\left[\mathrm{H}_{2} \mathrm{O}\right]}{k_{3} k_{6} k_{1 a}\left[\mathrm{~N}_{2}\right]}\right)\left(k_{10}[\mathrm{NO}]+\frac{k_{8}\left(J_{1 a}+J_{2}\right)\left[\mathrm{O}_{3}\right]}{k_{4 a}\left[\mathrm{~N}_{2}\right]\left[\mathrm{O}_{2}\right]}\right)} \\
{[\mathrm{OH}](40-60 \mathrm{~km}) \approx \sqrt{\left(\frac{k_{8}\left[\mathrm{H}_{2} \mathrm{O}\right]}{k_{3} k_{5}}\right)\left(\frac{k_{2} J_{1 a}\left[\mathrm{O}_{3}\right]}{k_{1 a}\left[\mathrm{~N}_{2}\right]}+J_{3}\right)}} \\
{[\mathrm{OH}](65-80 \mathrm{~km}) \approx \sqrt{\left(\frac{k_{8} J_{3}\left[\mathrm{H}_{2} \mathrm{O}\right]}{k_{3} k_{5}}\right)}}
\end{gathered}
$$

On the basis of these approximate solutions to the analytic model, we expect $[\mathrm{OH}] \propto \sqrt{\left(\left[\mathrm{H}_{2} \mathrm{O}\right]\right)}$ at $30-80 \mathrm{~km}$ altitude. This agrees with previous calculations for the stratosphere and mesosphere [Canty and Minschwaner, 2002]. Similarly, the analytic model predicts that $[\mathrm{OH}] \propto \sqrt{\left(\left[\mathrm{O}_{3}\right]\right)}$ at $40-$ $55 \mathrm{~km}$ altitude, but not at other altitudes. Above $55 \mathrm{~km}$, production of $\mathrm{HO}_{x}$ is increasingly dominated by $J_{3}$; below $40 \mathrm{~km},[\mathrm{OH}]$ is dependent on both $\left[\mathrm{O}_{3}\right]$ and $[\mathrm{NO}]$.

\section{Model Sensitivity Analyses}

[27] Sensitivity calculations using the analytic model were examined to identify the physical quantities that are expected to control the $\mathrm{OH}$ column abundance and to assess quantitatively how well the observed variations in the $\mathrm{OH}$ column over TMF could be explained by observed variations in controlling species, such as $\mathrm{H}_{2} \mathrm{O}$ and $\mathrm{O}_{3}$. The analytic model was more convenient for this purpose than the numerical model because the analytic model does not incorporate the automated feedback processes that are present in the numerical model. Thus each of the parameters affecting $\mathrm{OH}$ concentrations could be varied independently.

[28] Linear sensitivity coefficients for each of the controlling species in equation (9) were calculated at each altitude using equation (20).

$$
S_{i j}=\frac{\Delta\left(\ln [\mathrm{OH}]_{j}\right)}{\Delta\left(\ln [i]_{j}\right)}
$$

where $j$ defines the altitude layer within the analytic model, $i$ is the controlling species whose abundance is being varied, and $\ln$ is the natural logarithm. Equation (20) assumes the response function is linear and the tests we conducted by perturbing the concentrations of $\mathrm{H}_{2} \mathrm{O}, \mathrm{O}_{3}, \mathrm{NO}, \mathrm{CH}_{4}, \mathrm{HNO}_{3}$, and $\mathrm{CO}$ by $\pm 10 \%$ and $\pm 25 \%$ indicate there are no significant deviations from linearity over this range.

[29] In addition to the "local" effect of changes in the controlling species on the $\mathrm{OH}$ concentration, the partial column of $\mathrm{O}_{3}$ above each altitude affects the radiation field at lower altitudes and thus affects the production rate for $\mathrm{OH}$ via the production of $\mathrm{O}\left({ }^{1} \mathrm{D}\right)$. The photolysis rate for production of $\mathrm{O}\left({ }^{1} \mathrm{D}\right)$ from $\mathrm{O}_{3}$ is governed by the optical depth above each level in the atmosphere which is controlled primarily by the overhead partial column of $\mathrm{O}_{3}$ for the relevant wavelengths. For example, if the $\mathrm{O}_{3}$ above $40 \mathrm{~km}$ altitude is decreased uniformly by $25 \%$, then the optical depth above $40 \mathrm{~km}$ altitude will be decreased by $25 \%$. This will increase the actinic flux at $40 \mathrm{~km}$ altitude that can photolyze $\mathrm{O}_{3}$ to produce $\mathrm{O}\left({ }^{1} \mathrm{D}\right)$ and thus will increase the photolysis rate, $\mathrm{J}_{1}$, at $40 \mathrm{~km}$ altitude. A larger value for $J_{1}$ at $40 \mathrm{~km}$ altitude will increase the $\mathrm{OH}$ concentration at $40 \mathrm{~km}$ altitude. Thus a decrease in the $\mathrm{O}_{3}$ overhead above $40 \mathrm{~km}$ altitude leads to an increase in the $\mathrm{OH}$ concentration at $40 \mathrm{~km}$ altitude and an increase in the $\mathrm{OH}$ column abundance. Consequently, the "local photolytic" and "radiative" effects of changes in $\mathrm{O}_{3}$ concentrations have opposite sign and, as will be shown, can mostly cancel each other when integrated over the entire column. Because the overhead partial column of $\mathrm{O}_{3}$ determines the radiation field at each level at the relevant wavelengths for production of $\mathrm{O}\left({ }^{1} \mathrm{D}\right)$ and because $\mathrm{O}_{3}$ concentrations can be observed remotely (e.g., by HALOE) while vertical profiles of the actinic flux are not typically measured, the sensitivity of the $\mathrm{OH}$ column to the actinic flux has been expressed in terms of the overhead partial column of $\mathrm{O}_{3}$ ("OverO 3 ") (equation (21)).

$$
S_{j}\left(\text { OverO }_{3}\right)=\frac{\Delta\left(\ln [\mathrm{OH}]_{j}\right)}{\Delta\left(\ln \left(J_{1 a}+J_{1 b}\right)_{j}\right)} \frac{\Delta\left(\ln \left(J_{1 a}+J_{1 b}\right)_{j}\right)}{\Delta\left(\ln \left(\text { OverO }_{3}\right)_{j}\right)}
$$


The relationship between $\mathrm{J}_{1}$ and $\mathrm{OH}$ was approximately linear over the $\pm 25 \%$ range that was examined but the relationship between $\mathrm{J}_{1}$ and "OverO $\mathrm{O}_{3}$ " was not. This is the only significant uncertainty in any of the derived sensitivity coefficients other than the limitations imposed by the assumptions used in deriving the analytic model.

[30] To determine the effect that a change in a physical quantity at any altitude will have on the $\mathrm{OH}$ column, the sensitivity coefficient, $S_{i j}$, must be multiplied by the fraction of the $\mathrm{OH}$ column at that altitude to derive a weighting function (equation (22)).

$$
W_{i j}=S_{i j} \frac{[\mathrm{OH}]_{j} \Delta z_{j}}{\Sigma[\mathrm{OH}]_{j} \Delta z_{j}}
$$

where $\Delta z_{j}$ is the thickness of the altitude layer. The thickness of all altitude layers was $2 \mathrm{~km}$ for all of our calculations.

[31] The weighting function, $W_{i j}$, can be multiplied by the observed fractional change in a controlling species, $i$, at any altitude to determine the expected fractional change in the $\mathrm{OH}$ column. The expected fractional change in the $\mathrm{OH}$ column due to changes in multiple controlling species is then given by equation (23)

$$
\Delta\left(\ln \mathrm{OH}_{c}\right)=\Sigma_{j} \Sigma_{i} \Delta\left(\ln [i]_{j}\right) W_{i j}
$$

where $\mathrm{OH}_{c}$ is the $\mathrm{OH}$ column abundance. The weighting functions thus can be combined with observed changes in species concentrations (e.g., from HALOE) to calculate the expected fractional change in the $\mathrm{OH}$ column for comparison with the observed daily average variations as is discussed in the next section.

[32] As an initial assessment of which controlling species have significant influence on the $\mathrm{OH}$ column abundance, column sensitivity coefficients were calculated using equation (24).

$$
S_{i c}=\Sigma_{j} \frac{\Delta\left(\ln [\mathrm{OH}]_{j}\right)}{\Delta\left(\ln [i]_{j}\right)} \frac{[\mathrm{OH}]_{j} \Delta z_{j}}{\Sigma[\mathrm{OH}]_{j} \Delta z_{j}}
$$

where the fractional change in $[i]_{j}$ was assumed to be the same at all altitudes, $\pm 25 \%$. This range encompasses the

Table 2. Sensitivity of Modeled OH Column

\begin{tabular}{lccc}
\hline $\begin{array}{c}\text { Physical } \\
\text { Quantity }^{\mathrm{a}}\end{array}$ & $\begin{array}{c}\text { Range of Column } \\
\text { Sensitivity Coefficient }\end{array}$ & $\begin{array}{c}\text { Expected } \\
\text { Variation }\end{array}$ & $\begin{array}{c}\text { Range of Calculated } \\
\text { OH Column Response }\end{array}$ \\
\hline $\mathrm{H}_{2} \mathrm{O}$ & $49-51 \%$ & $\pm 25 \%$ & $\pm 12 \%$ \\
$\mathrm{O}_{3}$ & $35-45 \%$ & $\pm 25 \%$ & $\pm(9-11) \%$ \\
$\mathrm{NO}$ & $4-11 \%$ & & \\
$\mathrm{CO}$ & -1 to $-3 \%$ & & \\
$\mathrm{HNO}_{3}$ & -1 to $-5 \%$ & & \\
$\mathrm{CH}_{4}$ & $0.8-1.2 \%$ & & \\
$\mathrm{OverO}_{3}$ & -26 to $-89 \%$ & $\pm 25 \%$ & $\pm(-7$ to -22$) \%$ \\
\hline
\end{tabular}

${ }^{\text {a }}$ Physical quantity that was varied in the sensitivity calculation. Species abundances were changed at $0-130 \mathrm{~km}$ altitude. "OverO ${ }_{3}$ " is the partial column abundance of $\mathrm{O}_{3}$ above each layer in the photochemical model. "OverO ${ }_{3}$ " was varied to determine the effect of changes in the radiation field on $[\mathrm{OH}]$

${ }^{\mathrm{b}}$ Linearized $\mathrm{OH}$ column sensitivity coefficients $\left(\mathrm{S}_{i c}\right)$ computed using equation (24) and multiplied by 100 to express as a percentage. Values are a range, where the range encompasses the results from all six weighting functions shown in Figure 5.

${ }^{\mathrm{c}}$ Expected typical range of variability for the parameter within the $11-$ $81 \mathrm{~km}$ altitude region $\left(\Delta(\ln [i])_{c}\right)$ expressed as a percentage.

${ }^{\mathrm{d}}$ Calculated change induced in $\mathrm{OH}$ column abundance $\left(=\mathrm{S}_{i c} \times \Delta(\ln [i])_{c}\right)$ based on the expected variation in column 3 .

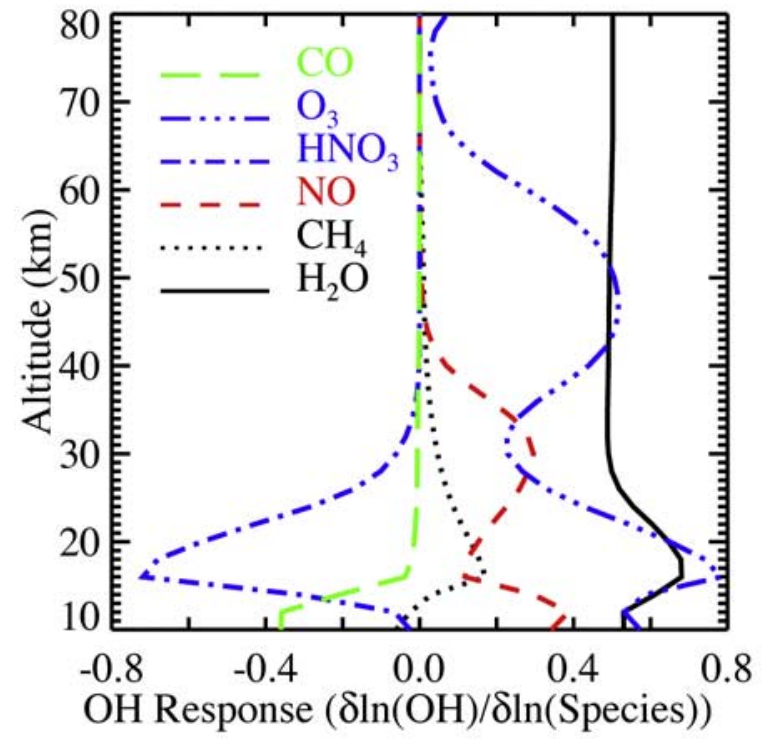

Figure 4. Sensitivity coefficients calculated as described in the text from the analytic model for changes in the concentrations of the species that are expected to influence $\mathrm{OH}$ concentrations at each altitude. All sensitivity coefficients were calculated for noontime conditions at spring equinox near $30^{\circ} \mathrm{N}$ latitude. The long-dashed line is for $\mathrm{CO}$, the dash-dot-dot-dot line is for $\mathrm{O}_{3}$, the dash-dot line is for $\mathrm{HNO}_{3}$, the short-dashed line is for $\mathrm{NO}$, the dotted line is for $\mathrm{CH}_{4}$, and the solid line is for $\mathrm{H}_{2} \mathrm{O}$.

range of variability expected for the primary physical quantities. The results from these column sensitivity calculations (Table 2, column 2) are normalized so they indicate the fractional change in the $\mathrm{OH}$ column abundance that would result if each physical quantity was changed by $100 \%$ at all altitudes $(0-130 \mathrm{~km})$. A negative sensitivity coefficient means the $\mathrm{OH}$ column change is opposite in sign to the change in that physical quantity. Column sensitivity coefficients for three times of day (morning at $60^{\circ} \mathrm{SZA}$, noon at $30^{\circ} \mathrm{SZA}$, and afternoon at $65^{\circ} \mathrm{SZA}$ ) were calculated using $\mathrm{OH}$ profiles that span the range of measurements reported by Pickett and Peterson [1996] and Conway et al. [2000]. Column sensitivity coefficients also were calculated for the noontime cases using recently proposed alternate kinetic rates [Sander et al., 2000, 2002; Summers et al., 1997]. The differences for $\mathrm{H}_{2} \mathrm{O}, \mathrm{O}_{3}$, "OverO 3 ," and NO from the results in Table 2, column 2, were no more than $2 \%$. The three parameters that are predicted to have the greatest influence on the $\mathrm{OH}$ column abundance are $\left[\mathrm{H}_{2} \mathrm{O}\right],\left[\mathrm{O}_{3}\right]$, and "OverO ${ }_{3}$," as expected [Pickett and Peterson, 1996].

[33] The sensitivity coefficients (Figure 4) are independent of the $\mathrm{OH}$ profile but may vary during a day if the dominant chemistry at an altitude changes. Most were found to vary only slightly throughout the range of SZA at which the $\mathrm{OH}$ column measurements over TMF are made, such as those in Figures A14 and A15. The sensitivity coefficient for "OverO ${ }_{3}$ " does vary significantly with the time of day (Figure A16). The sensitivity coefficients with the largest magnitudes are found at $15-20 \mathrm{~km}$ altitude where $\mathrm{OH}$ concentrations are most sensitive to the concentrations of 
$\mathrm{HNO}_{3}, \mathrm{H}_{2} \mathrm{O}$, and $\mathrm{O}_{3}$. At higher altitudes, where a majority of the $\mathrm{OH}$ column is predicted to be, $\mathrm{OH}$ concentrations are most sensitive to the concentrations of $\mathrm{H}_{2} \mathrm{O}$ and $\mathrm{O}_{3}$ with a weaker sensitivity to NO.

[34] The weighting functions are dependent on the shape of the $\mathrm{OH}$ profile. Three $\mathrm{OH}$ profiles that span the range of $\mathrm{OH}$ profiles (Figure A17) were selected for calculating the weighting functions for $\mathrm{H}_{2} \mathrm{O}, \mathrm{O}_{3}$, and "OverO ${ }_{3}$ " (Figure 5). The dependence on the shape of the $\mathrm{OH}$ profile is particularly significant for the $\mathrm{H}_{2} \mathrm{O}$ weighting function above $45 \mathrm{~km}$ altitude, and for $\mathrm{H}_{2} \mathrm{O}$ and $\mathrm{O}_{3}$, the weighting functions are significantly more sensitive to the $\mathrm{OH}$ profile than the smaller variations of the sensitivity coefficients with time of day. The weighting function for "OverO 3 " has comparable sensitivity to both the $\mathrm{OH}$ profile and the time of day (Figure 5a), and the weighting function for "OverO ${ }_{3}$ " is negative at most altitudes. The magnitude of the weighting function for "OverO ${ }_{3}$ " is approximately equal to that for $\mathrm{O}_{3}$ in the stratosphere, but the weighting function for "OverO 3 " has a greater dependence on the shape of the $\mathrm{OH}$ profile than is true for the $\mathrm{O}_{3}$ weighting function. Consequently, the net effect of changes in $\mathrm{O}_{3}$ concentrations will depend on the shape of the $\mathrm{OH}$ profile.

\section{Discussion}

\subsection{Comparison With Other Available $\mathrm{OH}$ Column Measurements}

[35] Column $\mathrm{OH}$ abundances have been measured over a number of sites as noted in section 1 . The four sites at which measurements have been made regularly for more than a year are Fritz Peak Observatory (FPO), Colorado, New Mexico Institute of Mining and Technology (NMT), New Mexico, University of Tokyo (Tokyo), Japan, and Table Mountain Facility (TMF), California. Significant, possibly systematic, differences have been noted among the column $\mathrm{OH}$ abundances measured over these sites [Mills et al., 2002; Iwagami et al., 1998]. To minimize the sensitivity to systematic errors, the present analysis has focused on the variations observed in the normalized $\mathrm{OH}$ column (i.e., deviations from the mean). A comparable analysis has not been completed for the Tokyo

Figure 5. (opposite) Weighting functions as defined in the text that give the response of the $\mathrm{OH}$ column to changes in (a) "OverO $\mathrm{O}_{3}$ " and to changes in (b) $\mathrm{O}_{3}$ and (c) $\mathrm{H}_{2} \mathrm{O}$ concentrations as a function of altitude for three $\mathrm{OH}$ profiles and two times of day. The noontime sensitivity coefficients were used for the curves shown in black, and the afternoon sensitivity coefficients were used for the curves shown in red (Figures A14, A15, and A16). The short-dashed line uses the empirical high-Sun $\mathrm{OH}$ profile from Canty et al. [2000], the dotted line uses the lower limit $\mathrm{OH}$ profile from MAHRSI's 1997 measurements [Conway et al., 2000], and the solid line uses the $\mathrm{OH}$ profile from the February 1992 model calculation of Pickett and Peterson [1996]. These $\mathrm{OH}$ profiles span the expected range (Figure A17). For "OverO 3 " the differences between noon and afternoon are comparable in magnitude to the differences among the $\mathrm{OH}$ profiles. For $\mathrm{O}_{3}$ and $\mathrm{H}_{2} \mathrm{O}$, the noon and afternoon curves are almost indistinguishable for almost all altitudes and all $\mathrm{OH}$ profiles.
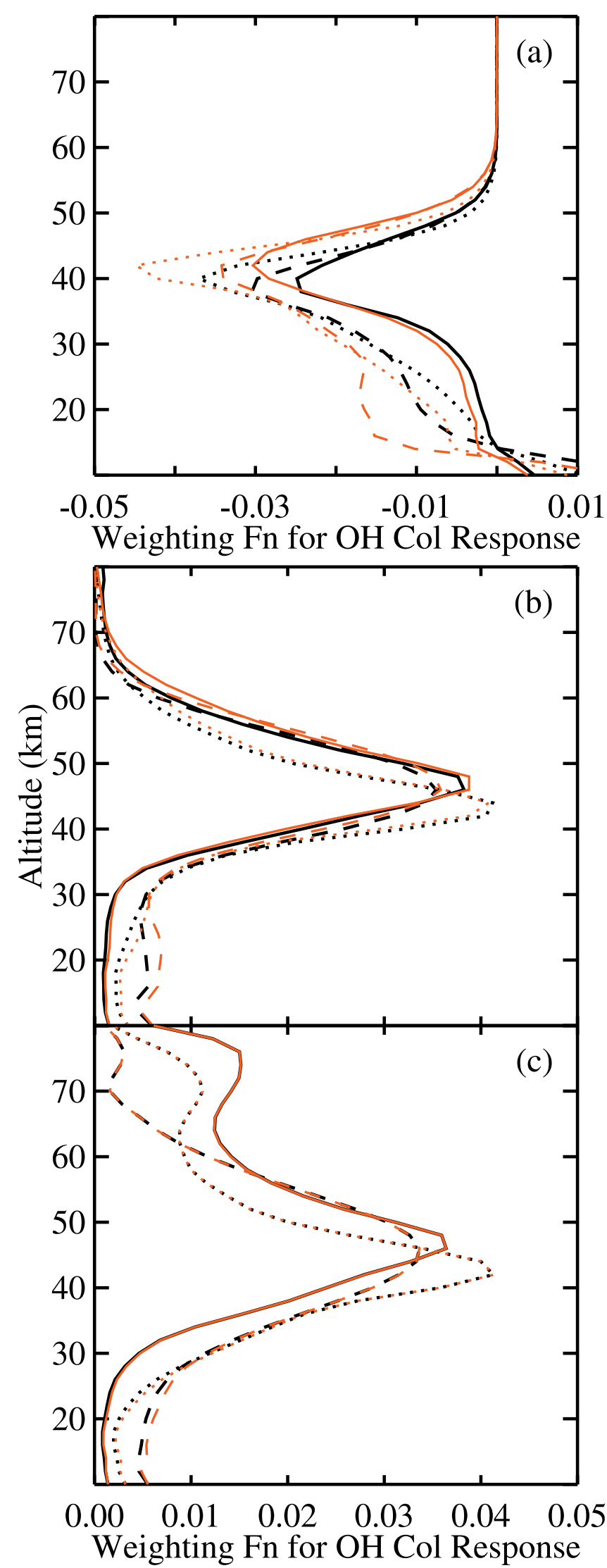
data, and the published Tokyo data do not permit a detailed analysis similar to what has been presented here. However, the peak-to-peak intra-annual variation in $\mathrm{P}_{1}(1) \mathrm{OH}$ column abundance observed "near-noon" over Tokyo in 19921995 [Iwagami et al., 1998] is similar to that observed over TMF in 1997-2001. The FPO and NMT data have been analyzed using a methodology that is similar to that used in the present study, and T. Canty (personal communication, 2003) provided the monthly average normalized $\mathrm{P}_{1}(1) \mathrm{OH}$ column abundances measured over FPO for the August 1997 to November 2000 time period [Canty and Minschwaner, 2002] for comparison with the TMF measurements over that time period. The variability about a linear fit to the monthly average FPO data obtained from August 1997 to November 2000 has a standard deviation of 0.07 . The variability about a linear fit to 30 -day averages of the normalized $\mathrm{P}_{1}(1) \mathrm{TMF}$ $\mathrm{OH}$ data from August 1997 to November 2000 has a standard deviation of 0.08 . A linear fit to the FPO data from August 1997 to November 2000 suggests an increase in the $\mathrm{OH}$ column abundance over FPO of about 30\% (difference divided by mean) over this time period. The corresponding increase over TMF for the same time period based on the linear fit in Figure 3 is $20 \%$. The difference in statistical variability is within the combined uncertainties on the two data sets. The difference in the magnitude of the interannual trends is not within the combined statistical uncertainties. This difference should be examined in greater detail after data has been collected for a longer time period over TMF to assess its geophysical significance.

\subsection{Measured Interannual and Intra-annual $\mathbf{O H}$ Column Variations}

[36] As shown in section 3 , the $\mathrm{OH}$ column abundance over TMF increased by about $25 \%$ (difference divided by mean) from July 1997 to December 2001. A similar interannual trend has been reported for the $\mathrm{OH}$ column abundance observed over FPO for 1997-2000 [Canty and Minschwaner, 2002]. The measurement time period of the current TMF data set is too short to provide a definitive conclusion regarding the cyclicality, amplitude, correlation with solar cycle, or origin of the observed interannual trend. However, if the interannual variation is cyclical and is connected to the solar cycle, then the amplitude of the increase in $\mathrm{OH}$ column abundance that was observed over TMF from 1997 to 2001 is at least a factor of 2 larger than model calculations predict ( $\sim 5-10 \%$ difference from solar maximum to minimum) [Mills et al., 2002; Canty and Minschwaner, 2002].

[37] On intra-annual timescales, statistically significant deviations from the empirical mean $\mathrm{OH}$ column of up to $+40 \%$ and $-50 \%$ are observed and variability on at least week-to-week or monthly timescales is readily apparent, section 3. As is also discussed in section 3, the observed variations in $\mathrm{OH}$ column appear to occur "uniformly" throughout the day. Our attempts to model the observed intra-annual variations are the subject for the remainder of section 6 .

\subsection{OH Column Variations Inferred From Measurements of Precursors}

[38] The model sensitivity analyses in section 5 suggest that the observed intra-annual variations in $\mathrm{OH}$ column abundance should be caused primarily by variations in the concentration of $\mathrm{H}_{2} \mathrm{O}$ and to a lesser extent $\mathrm{O}_{3}$. The remainder of this section compares the $\mathrm{OH}$ column abundance variations observed over TMF with those expected on the basis of observed variations in the concentrations of $\mathrm{H}_{2} \mathrm{O}$ and $\mathrm{O}_{3}$ near TMF and the weighting functions derived in section 5 . These comparisons are limited by the quality of the $\mathrm{OH}, \mathrm{H}_{2} \mathrm{O}$, and $\mathrm{O}_{3}$ measurements and by the degree to which these measurements are spatially and temporally coincident. The stratospheric ozone LIDAR at TMF can only measure $\mathrm{O}_{3}$ up to $\sim 50 \mathrm{~km}$ [Leblanc and McDermid, 2000]. The Naval Research Laboratory's (NRL) Water Vapor Millimeter-wave Spectrometer (WVMS) at TMF can only provide $\mathrm{H}_{2} \mathrm{O}$ concentrations above $45 \mathrm{~km}$ altitude [Nedoluha et al., 1995] and was not operating properly for at least 1998-2001. The Microwave Limb Sounder (MLS) aboard the Upper Atmosphere Research Satellite (UARS) [Barath et al., 1993] was operated very sporadically in 1997-2001 and one of its primary $\mathrm{O}_{3}$ measurement channels was not functioning. The Stratospheric Aerosol and Gas Experiment (SAGE) II does not provide $\mathrm{H}_{2} \mathrm{O}$ or $\mathrm{O}_{3}$ concentrations above $50 \mathrm{~km}$ altitude [Zaun et al., 1983]. Consequently, the only data set we found that provided measurements of $\mathrm{H}_{2} \mathrm{O}$ and $\mathrm{O}_{3}$ over the altitude range of at least $15-80 \mathrm{~km}$ for 1997-2001 was from the Halogen Occulation Experiment (HALOE) [Russell et al., 1993].

[39] HALOE measures species concentrations via sunrise and sunset occultations. We first selected all occultations that met our criteria (defined later) for spatial and temporal coincidence with the TMF OH column measurements. We then interpolated the measured HALOE (v. 19) concentrations onto a 2-km altitude grid from 12 to $80 \mathrm{~km}$ to match the grid used for the modeling. We divided the concentration at each altitude by the mean concentration measured at that altitude during the period July 1997 to December 2001. The measured vertical profiles of concentrations were thus converted into vertical profiles of the fractional deviation from the mean for each species. This was done separately for the sunrise and sunset occultations, but no significant differences in the temporal behavior of the sunset and sunrise data were evident. These fractional deviations from the mean are analogous to the normalized $\mathrm{OH}$ column abundances discussed in section 3 and are referred to hereafter as "normalized" species concentrations. The normalized species concentrations were multiplied by the altitude-dependent weighting functions (Figure 5) and summed as described by equation (23) to calculate the expected value for the normalized $\mathrm{OH}$ column on each day. The 2- $\sigma$ uncertainties on the HALOE measurements of each species at each altitude were converted into 2- $\sigma$ uncertainties on the normalized deviation from the mean using standard methods for propagating uncertainties [Bevington, 1969]. The 2- $\sigma$ uncertainty on the calculated normalized $\mathrm{OH}$ column abundance for each species was then determined in the standard manner [Bevington, 1969] by multiplying the uncertainty at each altitude by the weighting function for that altitude and summing the weighted uncertainties over all altitudes.

[40] Figure 6 shows the separate contributions from the normalized variations in $\mathrm{H}_{2} \mathrm{O}, \mathrm{O}_{3}$, and "OverO ${ }_{3}$ " when summed over the $11-81 \mathrm{~km}$ altitude region. A clear annual cycle is evident in all three contributions to the calculated 


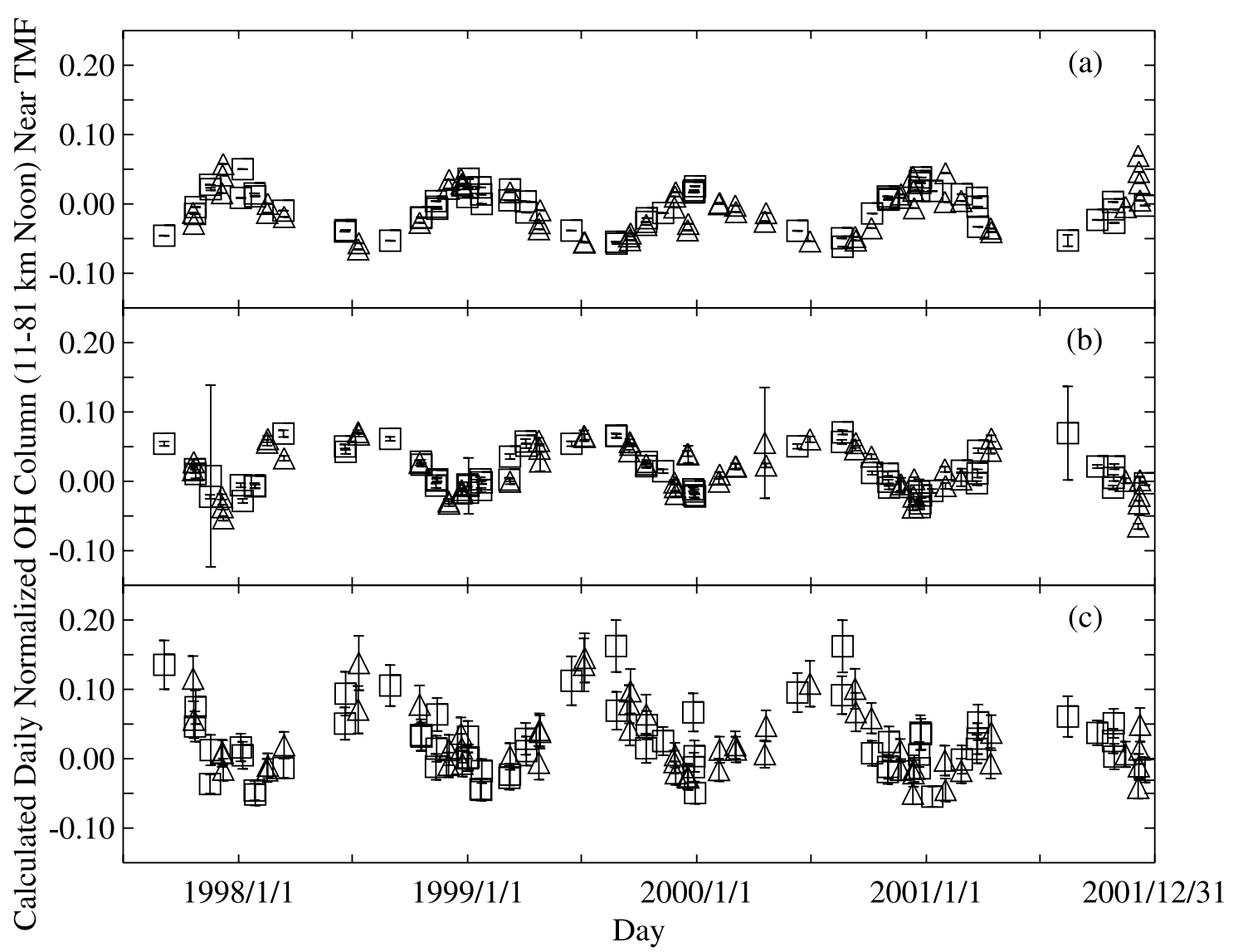

Figure 6. Daily average normalized $\mathrm{OH}$ columns calculated as described in the text based on the observed deviations from the mean $\mathrm{H}_{2} \mathrm{O}$ and $\mathrm{O}_{3}$ profiles for (a) "OverO $\mathrm{O}_{3}$," (b) $\mathrm{O}_{3}$, and (c) $\mathrm{H}_{2} \mathrm{O}$. The $\mathrm{OH}$ column variations were inferred on the basis of the noontime sensitivity coefficients (Figures A14, A15, and A16) and the nominal OH profile from MAHRSI's 1997 measurements [Conway et al., 2000]. All $\mathrm{H}_{2} \mathrm{O}$ and $\mathrm{O}_{3}$ observations obtained by $\operatorname{HALOE}(\mathrm{v} .19)$ on a single day within $5^{\circ}$ latitude and $10^{\circ}$ longitude of TMF at $11-81 \mathrm{~km}$ altitude were averaged to create the daily average $\mathrm{H}_{2} \mathrm{O}$ and $\mathrm{O}_{3}$ profiles. Uncertainties are $2 \sigma$ uncertainties from the HALOE measurements. The uncertainties in the weighting functions were not included. Triangles indicate that the HALOE measurements are from sunrise occultations, and squares indicate that the HALOE measurements are from sunset occultations.

$\mathrm{OH}$ column, but there is no corresponding clear signature of an annual cycle in the observed daily average $\mathrm{OH}$ column variations (Figure 3). It is also evident from Figure 6 that the contributions to the expected $\mathrm{OH}$ column variation from the normalized variations in $\mathrm{O}_{3}$ and " $\mathrm{OverO}_{3}$ " are opposite in sign and approximately equal in magnitude on a columnintegrated basis. Consequently, the contributions to the calculated $\mathrm{OH}$ column from $\mathrm{O}_{3}$ and "OverO${ }_{3}$ " should approximately cancel on a column-integrated basis and the calculated $\mathrm{OH}$ column variations should be dominated by the contribution from the normalized variations in $\mathrm{H}_{2} \mathrm{O}$.

[41] Figure 7 shows the calculated $\mathrm{OH}$ column variations using the noon weighting functions. Each of these calculations is the sum of the contributions due to variations in $\mathrm{H}_{2} \mathrm{O}, \mathrm{O}_{3}$, and "OverO 3 " at $11-81 \mathrm{~km}$. The 2- $\sigma$ uncertainties shown in Figure 7 are the root-sum-square of the 2- $\sigma$ uncertainties calculated for each of the three contributors $\left(\mathrm{H}_{2} \mathrm{O}, \mathrm{O}_{3}\right.$, and "OverO ${ }_{3}$ ") [Bevington, 1969]. The temporal pattern is similar for each of the three $\mathrm{OH}$ profiles, but the amplitude of the calculated $\mathrm{OH}$ column variation is significantly larger for the profile that has the largest fraction of the $\mathrm{OH}$ column in the mesosphere. Variations in the $\mathrm{OH}$ column are expected to be particularly sensitive to variations in mesospheric $\mathrm{H}_{2} \mathrm{O}$ because the observed fractional variations in $\mathrm{H}_{2} \mathrm{O}$ are larger in the mesosphere than in the stratosphere, albeit with greater uncertainties in the HALOE measurements.

\subsection{Statistical Comparisons of Measurements and Model Calculations}

[42] Two approaches have been taken for comparing the calculated and measured normalized $\mathrm{OH}$ column abundances. The first is to compare the statistical characteristics of the calculated and measured abundances. Because the normalized $\mathrm{OH}$ column abundances represent deviations from the mean, the primary statistical property of interest is the standard deviation for the normalized $\mathrm{OH}$ column abundances. The measured daily average normalized $\mathrm{P}_{1}(1)$ $\mathrm{OH}$ column abundance over TMF has a standard deviation of 0.12 . The mean $2 \sigma_{r}$ uncertainty on the measured daily average normalized $\mathrm{OH}$ column abundance is 0.05 so the observed variability is much larger than the measurement 


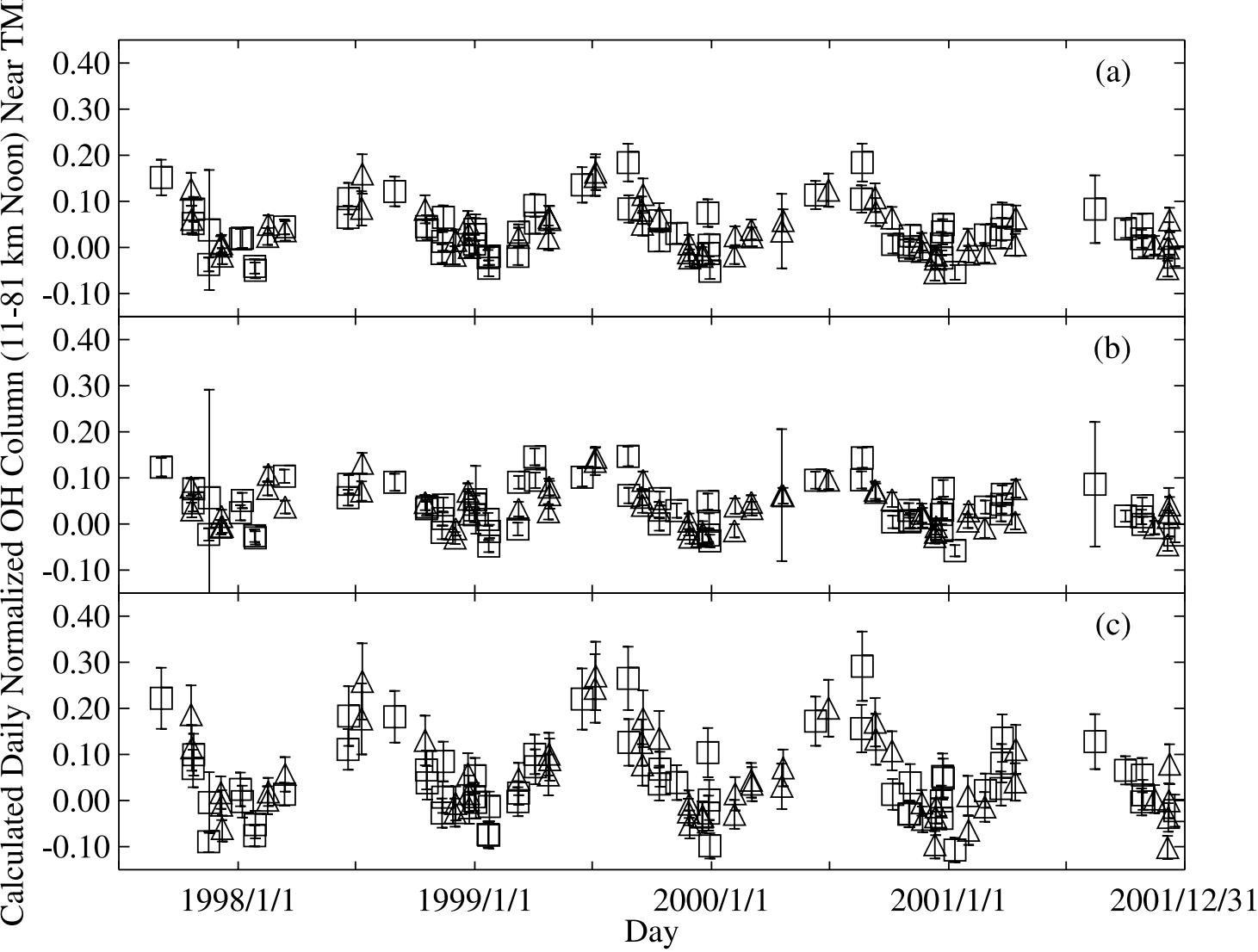

Figure 7. Daily average normalized $\mathrm{OH}$ columns calculated as described in the text based on the observed deviations from the mean $\mathrm{H}_{2} \mathrm{O}$ and $\mathrm{O}_{3}$ profiles. The $\mathrm{OH}$ column variations were inferred on the basis of the noontime sensitivity coefficients (Figures A14, A15, and A16) and three $\mathrm{OH}$ profiles that span the expected range (Figure A17). The three $\mathrm{OH}$ profiles illustrate the sensitivity of the calculated normalized $\mathrm{OH}$ column to the fraction of the $\mathrm{OH}$ column that is in the mesosphere: (a) the lower limit $\mathrm{OH}$ profile from MAHRSI's 1997 measurements [Conway et al., 2000] has a moderate fraction of the $\mathrm{OH}$ column above $60 \mathrm{~km}$ altitude, (b) the empirical high-Sun $\mathrm{OH}$ profile from Canty et al. [2000] has the smallest fraction of the $\mathrm{OH}$ column above $60 \mathrm{~km}$ altitude, and (c) the February 1992 model calculation from Pickett and Peterson [1996] has the largest fraction of the OH column above $60 \mathrm{~km}$ altitude. All $\mathrm{H}_{2} \mathrm{O}$ and $\mathrm{O}_{3}$ observations obtained by HALOE (v. 19) on a single day within $5^{\circ}$ latitude and $10^{\circ}$ longitude of TMF were averaged to create the daily average $\mathrm{H}_{2} \mathrm{O}$ and $\mathrm{O}_{3}$ profiles. Uncertainties are $2 \sigma$ uncertainties from the HALOE measurements. The uncertainties in the weighting functions were not included. Triangles indicate that the HALOE measurements are from sunrise occultations, and squares indicate that the HALOE measurements are from sunset occultations.

uncertainty. The calculated daily average normalized $\mathrm{OH}$ column abundance near TMF has a standard deviation of $0.05-0.09$ using the noon sensitivity coefficients and $0.04-$ 0.08 using the afternoon sensitivity coefficients. The greatest variability is found in calculations using the $\mathrm{OH}$ profile that has the largest fraction of the $\mathrm{OH}$ column in the mesosphere. The mean $2 \sigma$ uncertainty on the calculated daily average normalized $\mathrm{OH}$ column abundance is $0.03-$ 0.04 for both the noon and afternoon sensitivity coefficients, neglecting the uncertainties in the weighting functions. Consequently, for all three $\mathrm{OH}$ profiles and for both times of day, the variability in the calculated normalized $\mathrm{OH}$ column abundances is smaller than what is observed. The uncertainties on the measured and calculated daily average normalized $\mathrm{OH}$ column abundances are sufficiently small that the uncertainties cannot account for this difference between calculations and observations. Thus the greater variability in the observations is statistically significant.

[43] Three possible conclusions can be drawn from the difference between the standard deviations for the measured and calculated normalized $\mathrm{OH}$ column abundances. First, the fraction of the $\mathrm{OH}$ column in the mesosphere might be even larger than was assumed in the present study. This would contradict the results from the Middle Atmosphere High Resolution Spectrograph Investigation (MAHRSI) [Summers et al., 1997] and would disagree with the conclusions reached in other studies [Sandor and Clancy, 1998]. Second, the sensitivity coefficients for $\mathrm{H}_{2} \mathrm{O}$ derived from the analytic model may be a factor of 2 smaller than is true for the atmosphere. A study of interannual and seasonal variations of the $\mathrm{OH}$ column observed over Fritz Peak Observatory used different modeling and analysis methods, 
but it also suggested that the sensitivity coefficient for $\mathrm{H}_{2} \mathrm{O}$ should be a factor of 2 larger than predicted by present photochemical models [Canty and Minschwaner, 2002].

[44] Third, the observed variations in the $\mathrm{OH}$ column over TMF may be dominated by factors that have not been considered in the present study. One possibility is the tropospheric component of the $\mathrm{OH}$ column. Measurements of $\mathrm{OH}$ in the boundary layer have found variations in $\mathrm{OH}$ concentrations that could produce an $\sim 10 \%$ change in the $\mathrm{OH}$ column if the variations in $\mathrm{OH}$ concentration that have been observed in the boundary layer are representative of the entire troposphere [Mount et al., 1997; Canty et al., 2000]. At present there are too few measurements of $\mathrm{OH}$ in the free troposphere, particularly downwind of large urban centers like Los Angeles, to corroborate or refute this hypothesis.

\subsection{Comparisons of Near-Coincident Measurements and Model Calculations}

[45] Our second approach for comparing the calculated and measured normalized $\mathrm{OH}$ column abundances has been to select coincident or near-coincident days. Initially, we attempted to compare the measured and calculated normalized OH column abundances for days on which HALOE measurements above TMF were coincident with $\mathrm{OH}$ column measurements over TMF. However, both data sets are sufficiently sparse that there are only 6 days from July 1997 to December 2001 with temporally and spatially coincident measurements (i.e., on the same day within $5^{\circ}$ latitude and $10^{\circ}$ longitude of TMF). Relaxing the temporal coincidence criterion to \pm 1 day produces 20 near-coincident days (Figure 8) that are grouped into 13 clusters. Relaxing the temporal coincidence to \pm 1 day and the spatial coincidence to $\pm 10^{\circ}$ latitude and any longitude produces 75 nearcoincident days, but these near-coincident days are grouped into 26 clusters (with a typical interval between clusters of 1-2.5 months for the time periods where TMF data were collected regularly) and the averaged calculations may no longer be representative of the conditions at the time and location of the $\mathrm{OH}$ column measurements.

[46] Although some correlation between the calculated and measured normalized daily average $\mathrm{OH}$ column abundances is evident in Figure 8, the degree of correlation is much less than expected on the basis of the sensitivity analyses in section 5. However, the number of near-coincidences is too small to justify a definitive conclusion, particularly given the small number of near-coincidences in the months of February to October. No single weighting function (based on the three $\mathrm{OH}$ profiles and sensitivity coefficients from two times of day shown in Figure 5) produced a significantly better correlation between the calculated and measured normalized daily average $\mathrm{OH}$ column abundances than is shown in Figure 8. Timedependent calculations using the full Caltech/JPL photochemical model for the near-coincident days would be required to assess whether the $\mathrm{OH}$ profile on each of the near-coincident days changes by the amount that would be required to bring a majority of the calculated $\mathrm{OH}$ column abundances into agreement with the measured $\mathrm{OH}$ column abundances. However, simulations using multiple weighting functions from Figure 5 cannot eliminate the apparent disagreement between measurements and calculations in

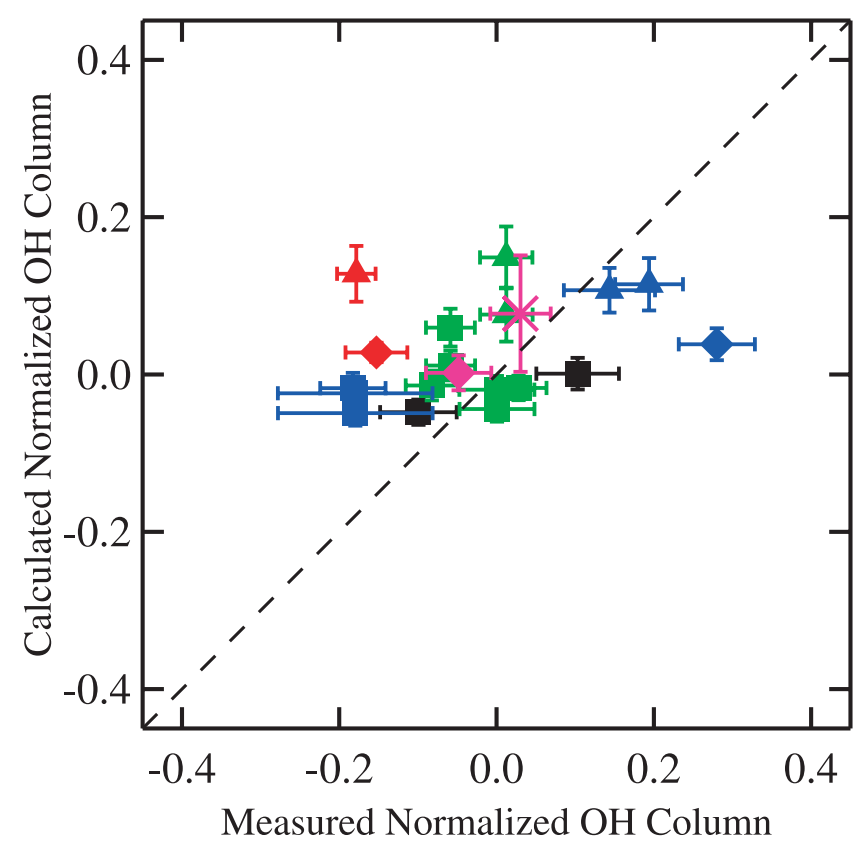

Figure 8. Calculated and measured normalized $\mathrm{OH}$ column abundances. The measured normalized $\mathrm{OH}$ column abundances are averages over 3 days. The interannual linear trend (Figure 3) has been subtracted from the measured normalized $\mathrm{OH}$ column abundances. The calculated normalized $\mathrm{OH}$ column abundances are averages over 1 day inferred from HALOE observations of $\mathrm{H}_{2} \mathrm{O}$ and $\mathrm{O}_{3}$ within $5^{\circ}$ latitude and $10^{\circ}$ longitude of TMF using the noontime sensitivity coefficients and the nominal $\mathrm{OH}$ profile derived from the 1997 MAHRSI measurements [Conway et al., 2000]. The black squares mark data from 5 December 1997 and 27 January 1998. The green triangles mark data from 10 and 11 July 1998. The green squares mark data from 1113 November 1998 and 21-23 January 1999. The red diamond marks the datum from 9 March 1999. The red triangle marks the datum from 15 June 1999. The blue diamond marks the datum from 2 March 2000. The blue triangles mark data from 9 and 29 June 2000 . The blue squares mark data from 10-12 December 2000. The purple diamond marks the datum from 13 April 2001. The purple "X" marks the datum from 14 August 2001. The short-dashed line indicates what would be expected if the measurements and calculations agreed perfectly.

Figure 8 . These weighting functions cover a broad range of atmospheric conditions, so we believe changes in the weighting function cannot resolve the apparent disagreement between measurements and calculations.

[47] The statistical comparisons in section 6.4 suggested that the actual sensitivity coefficient for variations in the concentration of $\mathrm{H}_{2} \mathrm{O}\left(S_{j}\left(\mathrm{H}_{2} \mathrm{O}\right)\right)$ may be a factor of 2 larger than was calculated from the analytic model. This was tested by doubling $S_{j}\left(\mathrm{H}_{2} \mathrm{O}\right)$ at $61-81,51-81$, and $11-$ $81 \mathrm{~km}$ altitude. Doubling $S_{j}\left(\mathrm{H}_{2} \mathrm{O}\right)$ increases the variability (one standard deviation) in the calculated normalized $\mathrm{OH}$ column abundance from 0.05 (using $S_{j}\left(\mathrm{H}_{2} \mathrm{O}\right)$ from the analytic model) to 0.08 (when doubling the sensitivity for 61-81 km), 0.08 (when doubling for $51-81 \mathrm{~km}$ ), and 0.10 (when doubling for $11-81 \mathrm{~km}$ ). When $S_{j}\left(\mathrm{H}_{2} \mathrm{O}\right)$ is doubled at 


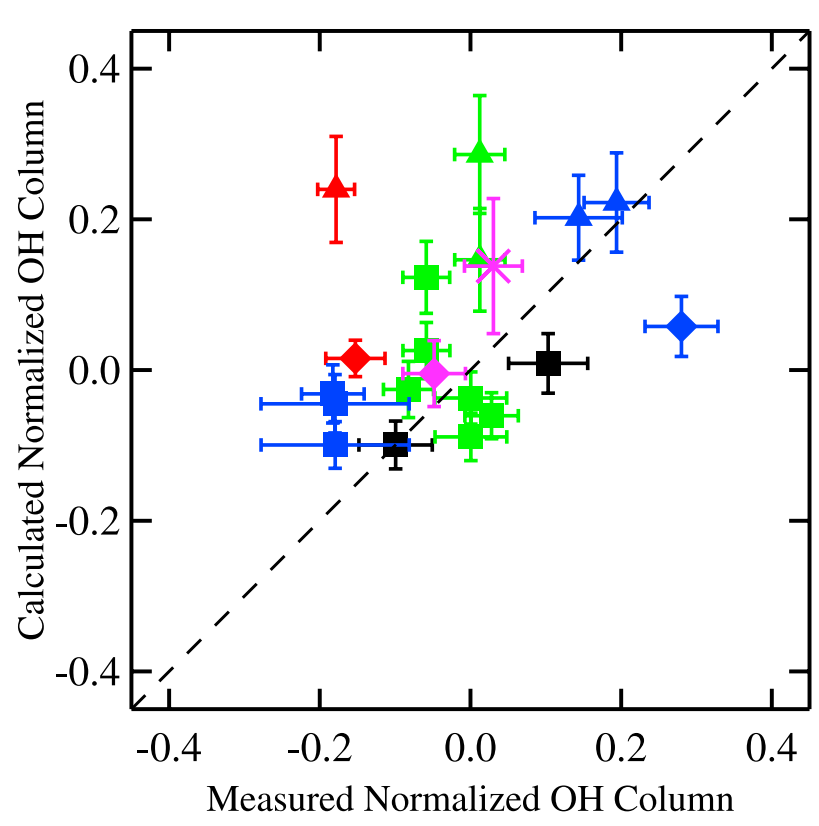

Figure 9. Same as Figure 8, but the sensitivity coefficients $\left(S_{j}\left(\mathrm{H}_{2} \mathrm{O}\right)\right)$ for variations in $\mathrm{H}_{2} \mathrm{O}$ concentrations at $11-81 \mathrm{~km}$ altitude have been doubled when determining the calculated normalized $\mathrm{OH}$ column abundances. The measured normalized $\mathrm{OH}$ column abundances are averages over 3 days. The interannual linear trend (Figure 3 ) has been subtracted from the measured normalized $\mathrm{OH}$ column abundances. The calculated normalized $\mathrm{OH}$ column abundances are averages over 1 day inferred from HALOE observations of $\mathrm{H}_{2} \mathrm{O}$ and $\mathrm{O}_{3}$ within $5^{\circ}$ latitude and $10^{\circ}$ longitude of TMF using the noontime sensitivity coefficients for $\mathrm{O}_{3}$ and "OverO 3 ," double the noontime sensitivity coefficients for $\mathrm{H}_{2} \mathrm{O}$, and the nominal OH profile derived from the 1997 MAHRSI measurements [Conway et al., 2000]. The black squares mark data from 5 December 1997 and 27 January 1998. The green triangles mark data from 10 and 11 July 1998. The green squares mark data from 11-13 November 1998 and 21-23 January 1999. The red diamond marks the datum from 9 March 1999. The red triangle marks the datum from 15 June 1999. The blue diamond marks the datum from 2 March 2000. The blue triangles mark data from 9 and 29 June 2000. The blue squares mark data from 10-12 December 2000. The purple diamond marks the datum from 13 April 2001. The purple " $X$ " marks the datum from 14 August 2001. The short-dashed line indicates what would be expected if the measurements and calculations agreed perfectly. Doubling the $\mathrm{H}_{2} \mathrm{O}$ sensitivity coefficients produces better agreement between calculations and measurements, but the scatter about the expected line is large.

$11-81 \mathrm{~km}$ altitude, the variability in the calculated normalized $\mathrm{OH}$ column abundance becomes comparable to the 0.12 variability that is observed over TMF. As shown in Figure 9, however, the degree of correlation between the calculated and measured normalized $\mathrm{OH}$ columns does not change significantly. No single weighting function from Figure 5 produced a significantly better correlation between the calculated and measured normalized daily average $\mathrm{OH}$ column abundances than is shown in Figure 9. The result shown in Figure 9 plus the negative result from using multiple $\mathrm{OH}$ profiles for simulations (above) suggests that doubling the sensitivity coefficient for variations in $\mathrm{H}_{2} \mathrm{O}$ will not be sufficient for resolving the differences that exist between observations and calculations. If the estimated uncertainties for the TMF measurements [Cageao et al., 2001] are correct, then other factors that have not been examined in this manuscript must exert significant influence on the $\mathrm{OH}$ column abundance.

\section{Summary and Conclusions}

[48] Measurements of the $\mathrm{OH}$ column abundance over the Jet Propulsion Laboratory's Table Mountain Facility (TMF) have been made since July 1997 at $10^{\circ}-80^{\circ}$ solar zenith angle using a Fourier transform ultraviolet spectrometer (FTUVS). An empirical least squares fit describing the annual average $\mathrm{OH}$ column as a function of solar zenith angle has been derived. The measured $\mathrm{OH}$ column at any solar zenith angle is typically larger in the afternoon than in the morning. The variations observed in the normalized $\mathrm{OH}$ column abundance appear to be the result of changes in atmospheric conditions that occur on a daily or longer timescales. The magnitude of the variations observed in the daily average of the normalized $\mathrm{OH}$ column abundance is larger than the uncertainties on the daily averages, implying the observed variations are statistically significant.

[49] An updated analytic model that describes the $\mathrm{OH}$ concentration at $25-70 \mathrm{~km}$ altitude was derived and used to calculate sensitivity coefficients that describe how the $\mathrm{OH}$ concentration and the $\mathrm{OH}$ column abundance are expected to change in response to changes in the concentrations of $\mathrm{H}_{2} \mathrm{O}, \mathrm{O}_{3}, \mathrm{NO}, \mathrm{CO}$, and $\mathrm{CH}_{4}$. On the basis of the modeled sensitivity coefficients and HALOE observations of $\mathrm{O}_{3}$ concentrations, the net sensitivity of the $\mathrm{OH}$ column abundance to variations in $\mathrm{O}_{3}$ concentrations is close to zero because the radiative (overhead optical depth) and local photolytic effects approximately cancel when integrated over the entire column. Consequently, variations in the $\mathrm{OH}$ column abundance are expected to be dominated by variations in $\mathrm{H}_{2} \mathrm{O}$ concentrations.

[50] The observed $\mathrm{OH}$ column over TMF increased by about 25\% from July 1997 to December 2001. No significant interannual trend is apparent in the modeled $\mathrm{OH}$ column for this time period so the observed trend in the $\mathrm{OH}$ column abundance is not due to the observed interannual trends in $\mathrm{H}_{2} \mathrm{O}$ or $\mathrm{O}_{3}$ concentrations. The observed interannual $\mathrm{OH}$ column trend is at least a factor of 2 larger than the calculated difference between solar minimum and maximum. On a daily average basis, the observed variations in the normalized $\mathrm{OH}$ column abundance are a factor of 2 larger than calculated on the basis of HALOE observations of $\mathrm{H}_{2} \mathrm{O}$ and $\mathrm{O}_{3}$. This suggests that the sensitivity of $\mathrm{OH}$ concentrations to variations in $\mathrm{H}_{2} \mathrm{O}$ concentrations is a factor of 2 larger than predicted in present models. However, doubling the sensitivity of $\mathrm{OH}$ concentrations to variations in $\mathrm{H}_{2} \mathrm{O}$ does not, by itself, resolve the relatively poor correlation between calculated and measured normalized $\mathrm{OH}$ column abundances for the small number of days on which near-coincident measurements were made of $\mathrm{OH}$ column and $\mathrm{H}_{2} \mathrm{O}$ and $\mathrm{O}_{3}$ concentration profiles. These results suggest that there is some other major driver for 
the observed variability in the $\mathrm{OH}$ column abundance that was not examined in the present study. One possibility is the troposphere. Substantial variations have been reported for $\mathrm{OH}$ concentrations in the boundary layer between "clean" and "urban" air, but no similar time series of measurements exists for the free troposphere.

[51] The present analysis is limited by the small number of coincident measurements of $\mathrm{OH}$ column abundance, $\mathrm{H}_{2} \mathrm{O}$, and $\mathrm{O}_{3}$. Coincident, colocated measurements of $\mathrm{OH}$ column abundance along with profiles for at least $30-70 \mathrm{~km}$ altitude of $\mathrm{H}_{2} \mathrm{O}, \mathrm{O}_{3}$, and temperature are needed.

[52] The $\mathrm{OH}$ column measurements over TMF that were described in this publication will be placed in the NDSC archive after they are brought to a consistent processing level.

\section{Future Work}

[53] Several types of additional measurements are required to examine questions raised in the present research. Further $\mathrm{OH}$ column measurements are needed to assess whether the upward trend in $\mathrm{OH}$ column abundance seen from 1997 to 2001 is cyclical. Two types of data intercomparisons are needed [Mills et al., 2002]: (1) coincident $\mathrm{OH}$ column abundance and $\mathrm{OH}$ profile measurements and (2) intercomparisons of $\mathrm{OH}$ column abundances from different instruments. These intercomparisons will help resolve existing questions regarding the systematic differences between data sets. Ideally, coincident observations of $\mathrm{OH}$ column abundance along with vertical profiles of $\mathrm{OH}, \mathrm{HO}_{2}$, $\mathrm{O}_{3}, \mathrm{H}_{2} \mathrm{O}$, and temperature over at least $30-70 \mathrm{~km}$ altitude are needed. This might be possible if coincident observations by Odin [Murtagh et al., 2002], SABER http://asdwww.larc.nasa.gov/saber/ASDsaber.html), and SHIMMER http://uap-www.nrl.navy.mil/shimmer/shimmer.htm) can be arranged. Regular $\mathrm{OH}$ concentration measurements in the free troposphere, particularly downwind of large urban areas like Los Angeles, are needed to assess what fraction of the observed variability in the $\mathrm{OH}$ column is due to fluctuations in the $\mathrm{OH}$ concentration in the free troposphere.

[54] Acknowledgments. The research described in this paper was performed at the Jet Propulsion Laboratory, California Institute of Technology. Support received from the NASA Upper Atmosphere Research Program, the California Institute of Technology President's Fund, the Naval Research Laboratory, and NASA grants NAG1-1806 and NAG1-2151 to the California Institute of Technology is gratefully acknowledged. The authors thank Vassilli Nemtchinov and Yibo Jiang for their contributions to the collection and processing of the $\mathrm{OH}$ column measurements, Timothy Canty for his assistance in comparing the TMF and FPO measurements, and Fok-Yan Leung for assistance with the final versions of figures. Helpful suggestions from an anonymous reviewer are gratefully acknowledged. The HALOE data were obtained via http://haloedata.larc.nasa.gov.

\section{References}

Allen, M., and M. L. Delitsky, A test of odd-oxygen photochemistry using Spacelab-3 Atmospheric Trace Molecule Spectroscopy observations, J. Geophys. Res., 96, 12,883-12,891, 1991.

Allen, M., and J. E. Frederick, Effective photo-dissociation cross sections for molecular oxygen and nitric-oxide in the Schumann-Runge bands, J. Atmos. Sci., 39, 2066-2075, 1982.

Allen, M., Y. L. Yung, and J. W. Waters, Vertical transport and photochemistry in the terrestrial mesosphere and lower thermosphere $(50-120 \mathrm{~km})$, J. Geophys. Res., 86, 3617-3627, 1981.

Barath, F. T., et al., The Upper Atmosphere Research Satellite Microwave Limb Sounder instrument, J. Geophys. Res., 98, 10,751-10,762, 1993.

Bevington, P. R., Data Reduction and Error Analysis for the Physical Sciences, 336 pp., McGraw-Hill, New York, 1969.
Burnett, C. R., and E. B. Burnett, Spectroscopic measurements of the vertical column abundance of hydroxyl $(\mathrm{OH})$ in the Earth's atmosphere, J. Geophys. Res., 86, 5185-5202, 1981.

Burnett, C. R., and E. B. Burnett, The regime of decreased $\mathrm{OH}$ vertical column abundances at Fritz Peak Observatory, CO: 1991-1995, Geophys. Res. Lett., 23, 1925-1927, 1996.

Burnett, C. R., and K. Minschwaner, Continuing development in the regime of decreased atmospheric column $\mathrm{OH}$ at Fritz Peak, Colorado, Geophys. Res. Lett., 25, 1313-1316, 1998.

Cageao, R. P., Y. L. Ha, Y. Jiang, M. F. Morgan, Y. L. Yung, and S. P. Sander, Calculated hydroxyl $\mathrm{A}^{2} \Sigma^{+} \rightarrow \mathrm{X}^{2} \Pi(0,0)$ band emission rate factors applicable to atmospheric spectroscopy, J. Quant. Spectrosc. Radiat. Transfer, 57, 703-717, 1997

Cageao, R. P., J.-F. Blavier, J. P. McGuire, Y. Jiang, V. Nemtchinov, F. P. Mills, and S. P. Sander, High-resolution Fourier-transform ultravioletvisible spectrometer for the measurement of atmospheric trace species: Application to OH, Appl. Opt., 40, 2024-2030, 2001.

Canty, T., and K. Minschwaner, Seasonal and solar cycle variability of $\mathrm{OH}$ in the middle atmosphere, J. Geophys. Res., 107(D24), 4737, doi:10.1029/2002JD002278, 2002.

Canty, T., K. Minschwaner, K. W. Jucks, and A. K. Smith, A review of hydroxyl in the middle atmosphere: Comparison of measured and modeled vertical profiles and ground-based column observations, in Atmospheric Science Across the Stratopause, Geophys. Monogr. Ser., vol. 123, edited by D. E. Siskind, S. D. Eckermann, and M. E. Summers, pp. $131-$ 136, AGU, Washington, D. C., 2000.

Conway, R. R., M. E. Summers, M. H. Stevens, J. G. Cardon, P. Preusse, and D. Offermann, Satellite observations of upper stratospheric and mesospheric $\mathrm{OH}$ : The $\mathrm{HO}_{x}$ dilemma, Geophys. Res. Lett., 27, 26132616, 2000.

DeMore, W. B., S. P. Sander, D. M. Golden, R. F. Hampson, M. J. Kurylo, C. J. Howard, A. R. Ravishankara, C. E. Kolb, and M. J. Molina, Chemical Kinetics and Photochemical Data for Use in Stratospheric Modeling: Evaluation Number 12, JPL Publ., 97-4, 266 pp., 1997.

Froidevaux, L., M. Allen, and Y. L. Yung, A critical analysis of $\mathrm{ClO}$ and $\mathrm{O}_{3}$ in the mid-latitude stratosphere, J. Geophys. Res., 90, 12,999-13,029, 1985.

Gillis, J. R., A. Goldman, G. Stark, and C. P. Rinsland, Line parameters for the $A^{2} \Sigma^{+}-X^{2} \Pi$ bands of OH, J. Quant. Spectrosc. Radiat. Transfer, 68, $225-230,2001$.

Hofmann, D. J., et al., Predicting future ozone changes and detection of recovery, in Scientific Assessment of Ozone Depletion: 1998, edited by D. L. Albritton et al., pp. 12.1-12.57, World Meteorol. Organ., Geneva, 1999.

Iwagami, N., S. Inomata, I. Murata, and T. Ogawa, Doppler detection of hydroxyl column abunance in the middle atmosphere, J. Atmos. Chem., 20, 1-15, 1995 .

Iwagami, N., S. Inomata, and T. Ogawa, Doppler detection of hydroxyl column abundance in the middle atmosphere: 2. Measurement for three years and comparison with a 1D model, J. Atmos. Chem., 29, 195-216, 1998.

Jucks, K. W., D. G. Johnson, K. V. Chance, W. A. Traub, J. J. Margitan, G. B. Osterman, R. J. Salawitch, and Y. Sasano, Observations of OH, $\mathrm{HO}_{2}, \mathrm{H}_{2} \mathrm{O}$, and $\mathrm{O}_{3}$ in the upper stratosphere: Implications for $\mathrm{HO}_{x}$ photochemistry, Geophys. Res. Lett., 25, 3935-3938, 1998.

Leblanc, T., and I. S. McDermid, Stratospheric ozone climatology from lidar measurements at Table Mountain $\left(34.4^{\circ} \mathrm{N}, 117.7^{\circ} \mathrm{W}\right)$ and Mauna Loa $\left(9.5^{\circ} \mathrm{N}, 155.6^{\circ} \mathrm{W}\right)$, J. Geophys. Res., 105, 14,613-14,623, 2000.

Mills, F. P., R. P. Cageao, V. Nemtchinov, Y. Jiang, and S. P. Sander, OH column abundance over Table Mountain Facility, California: Annual average 1997-2000, Geophys. Res. Lett., 29(15), 1742, doi:10.1029/ 2001GL014151, 2002.

Mount, G. H., J. W. Brault, P. V. Johnston, E. Marovich, R. O. Jakoubek, C. J. Volpe, J. Harder, and J. Olson, Measurement of tropospheric $\mathrm{OH}$ by long-path laser absorption at Fritz Peak Observatory, Colorado, during the OH Photochemistry Experiment, Fall 1993, J. Geophys. Res., 102, 6393-6413, 1997.

Müller, R., et al., Upper stratospheric processes, in Scientific Assessment of Ozone Depletion: 1998, edited by D. L. Albritton et al., pp. 6.1-6.44, World Meteorol. Organ., Geneva, 1999.

Murtagh, D., et al., An overview of the Odin atmospheric mission, Can. J. Phys., 80, 309-319, 2002.

Nedoluha, G. E., R. M. Bevilacqua, R. M. Gomez, D. L. Thacker, W. B. Waltman, and T. A. Pauls, Ground-based measurements of water vapor in the middle atmosphere, J. Geophys. Res., 100, 2927-2939, 1995.

Notholt, J., H. Schutt, and A. Keens, Solar absorption measurements of stratospheric $\mathrm{OH}$ in the UV with a Fourier-transform spectrometer, Appl. Opt., 36, 6076-6082, 1997.

Pickett, H. M., and D. B. Peterson, Comparison of measured stratospheric OH with prediction, J. Geophys. Res., 101, 16,789-16,796, 1996. 
Press, W. H., B. P. Flannery, S. A. Teukolsky, and W. T. Vetterling, Numerical Recipes: The Art of Scientific Computing (FORTRAN version), 702 pp., Cambridge Univ. Press, New York, 1989.

Russell, J. M., L. L. Gordley, J. H. Park, S. R. Drayson, W. D. Hesketh, R. J. Cicerone, A. F. Tuck, J. E. Frederick, J. E. Harries, and P. J. Crutzen, The Halogen Occultation Experiment, J. Geophys. Res., 98, 10,777-10,797, 1993.

Sander, S. P., et al., Chemical Kinetics and Photochemical Data for Use in Stratospheric Modeling: Evaluation Number 13, JPL Publ., 00-3, 74 pp., 2000

Sander, S. P., et al., Chemical Kinetics and Photochemical Data for Use in Atmospheric Studies: Evaluation Number 14, JPL Publ., 02-25, 2002.

Sandor, B. J., and R. T. Clancy, Mesospheric $\mathrm{HO}_{x}$ chemistry from diurnal microwave observations of $\mathrm{HO}_{2}, \mathrm{O}_{3}$, and $\mathrm{H}_{2} \mathrm{O}, J$. Geophys. Res., 103, 13,337-13,351, 1998.

Stark, G., J. W. Brault, and M. C. Abrams, Fourier-transform spectra of the $A^{2} \Sigma^{+}-X^{2} \Pi \Delta v=0$ bands of $\mathrm{OH}$ and OD, J. Opt. Soc. Am. B Opt. Phys., 11, 3-32, 1994 .

Summers, M. E., R. R. Conway, D. E. Siskind, M. H. Stevens, D. Offermann, M. Riese, P. Preusse, D. F. Strobel, and J. M. Russell III, Implications of satellite $\mathrm{OH}$ observations for middle atmospheric $\mathrm{H}_{2} \mathrm{O}$ and ozone, Science, 277, 1967-1970, 1997
Zaun, N. H., L. E. Mauldin, and M. P. McCormick, Design and performance of the Stratospheric Aerosol and Gas Experiment-II (SAGE-II) instrument, Proc. SPIE Int. Soc. Opt. Eng., 430, 99-105, 1983.

M. Allen, Jet Propulsion Laboratory, California Institute of Technology, MS 183-401, 4800 Oak Grove Drive, Pasadena, CA 91109, USA.

R. P. Cageao and S. P. Sander, Jet Propulsion Laboratory, California Institute of Technology, MS 183-901, 4800 Oak Grove Drive, Pasadena, CA 91109, USA.

F. P. Mills, Research School of Physical Sciences and Engineering, Australian National University, Canberra ACT 0200, Australia. (frank. mills@anu.edu.au)

E. E. Remsberg, NASA Langley Research Center, MS 401B, 21 Langley Boulevard, Hampton, VA 23681, USA.

U. Richter, California Institute of Technology, M/C 138-78, 1201 E. California Boulevard, Pasadena, CA 91125, USA.

J. M. Russell III, Center for Atmospheric Sciences, Hampton University, P. O. Box 6075, Hampton, VA 23668, USA.

Y. L. Yung, California Institute of Technology, M/C 150-21, 1201 E. California Boulevard, Pasadena, CA 91125, USA. 